\title{
Controls of inherited lithospheric heterogeneity on rift linkage: Numerical and analog models of interaction between the Kenyan and Ethiopian rifts across the Turkana depression
}

\author{
Sascha Brune ${ }^{\mathrm{a}, \mathrm{b}}$, Giacomo Cortic ${ }^{\mathrm{c}}$, Giorgio Ranalli ${ }^{\mathrm{d}}$ \\ ${ }^{a}$ German Research Centre for Geosciences GFZ, Potsdam, Germany \\ ${ }^{\mathrm{b}}$ Institute of Earth and Environmental Sciences, University of Potsdam, Germany; \\ ${ }^{\mathrm{c}}$ Istituto di Geoscienze e Georisorse, Consiglio Nazionale delle Ricerche, Florence, Italy \\ ${ }^{\mathrm{d}}$ Department of Earth Sciences and Ottawa-Carleton Geoscience Centre, Carleton University, Ottawa, Canada
}

\begin{abstract}
Inherited rheological structures in the lithosphere are expected to have large impact on the architecture of continental rifts. The Turkana depression in the East African Rift connects the Main Ethiopian Rift to the north with the Kenya rift in the south. This region is characterized by a NW-SE trending band of thinned crust inherited from a Mesozoic rifting event, which is cutting the present-day N-S rift trend at high angle. In striking contrast to the narrow rifts in Ethiopia and Kenya, extension in the Turkana region is accommodated in sub-parallel deformation domains that are laterally distributed over several hundred kilometers. We present both analog experiments and numerical models that reproduce the along-axis transition from narrow rifting in Ethiopia and Kenya to a distributed deformation within the Turkana depression. Similarly to natural observations, our models show that the Ethiopian and Kenyan rifts bend away from each other within the Turkana region, thus forming a right-lateral stepover and avoiding a direct link to form a continuous N-S depression. The models reveal five potential types of rift linkage across the pre-existing basin: three types where rifts bend away from the inherited structure connecting via a (1) wide or (2) narrow rift or by (3) forming a rotating microplate, (4) a type where rifts bend towards it, and (5) straight rift linkage. The fact that linkage type 1 is realized in the Turkana region provides new insights on the rheological configuration of the Mesozoic rift system at the onset of the recent rift episode.
\end{abstract}

\section{Introduction}

The evolution and architecture of continental rifts is controlled by the interaction among several parameters, including the rate of plate divergence, the thermal state of the lithosphere, and the presence and volumes of magmatic products [e.g. Ziegler and Cloetingh, 2004; Brune, 2016]. However, almost all continental rifts form in pre-deformed, and thus already structured, anisotropic lithosphere and reactivate pre-existing weak zones, such as mobile belts, while avoiding stronger regions, such as cratons [e.g. Dunbar and Sawyer, 1988; Versfelt and Rosendahl, 1989]. The pre-rift lithospheric rheological structure and in particular its along-axis variations play one of the most important roles during continental extension.

The East African Rift (EAR) is a classical example where rifts are guided by inherited structures. The rift system developed within a region that has experienced several deformation events, from different phases of collision during the Precambrian to Mesozoic extension [Chorowicz, 2005]. This complex tectonic history has given rise to 
significant lateral variations in the rheological structure of the lithosphere [Ebinger et al., 1997], which in turn have played a major role in rift evolution. This is clearly testified by the localization and propagation of major rift segments within weak Proterozoic mobile belts, which surround the undeformed Tanzania craton [Chorowicz, 2005 and references therein]. Linking and mechanical interaction between adjacent rift segments has typically occurred in correspondence to transverse pre-existing fabrics, where structurally complex areas (transfer zones) have allowed significant along-axis variations in subsidence of grabens and elevation of uplifted flanks [Rosendahl, 1987; Morley et al., 1990; Faulds and Varga, 1998; Morley, 1999].

One of these complex areas is the Turkana depression, the region of interaction between the Ethiopian and Kenyan rifts, which is characterized by anomalous morphology and architecture with respect to the rift valleys in Kenya and Ethiopia. In this paper we test the hypothesis that these anomalies result from the presence of a preexisting rift, transverse to the trend of the rift valleys and characterized by thin crust and lithosphere. To this aim, we complement crustal-scale centrifuge analog models with lithospheric-scale numerical modeling.

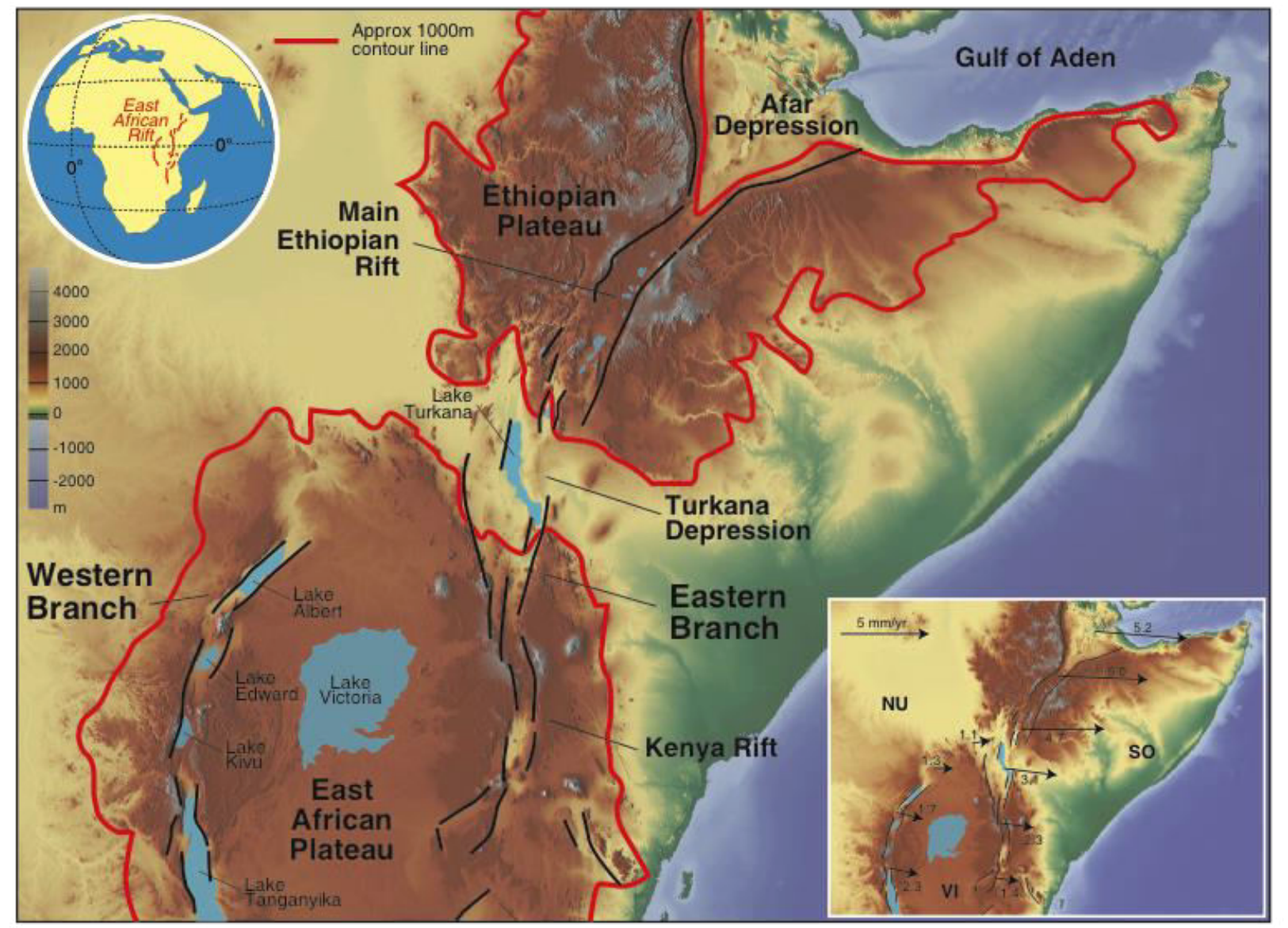

Fig. 1. Tectonic setting of the East African Rift. Schematic fault pattern and present-day plate kinematics (inset). Black arrows show relative motions with respect to a stable Nubian reference frame according to the best-fit model of Saria et al. [2014]. Values besides arrows indicate motion in mm/yr. NU: Nubian plate; SO: Somalian plate; VI: Victoria microplate. 


\section{Tectonic setting}

The Turkana depression is a low-land located between the uplifted East African and Ethiopian domes (Fig. 1). The tectonic setting of this area is controlled by long-term divergence between the Nubian and Somalian plates, which is currently occurring in a roughly E-W direction at rates of a few mm/yr [Saria et al., 2014; Stamps et al., 2014]. Recent plate motion models [laffaldano et al., 2014; DeMets and Merkouriev, 2016] suggest that this direction of extension has likely remained steady during rift development (i.e., in the last 10-12 My).

The Main Ethiopian Rift (MER) and the Kenya Rift are part of the Eastern Branch of the EAR (Fig. 1) [Chorowicz, 2005]. North of the Turkana region, in the MER and southern portion of the Afar depression, extensional deformation is characterized by a typical narrow rift morphology exhibiting large fault escarpments with vertical displacement of $>1 \mathrm{~km}$, which bound a roughly $80-100 \mathrm{~km}$ wide rift valley and separate two uplifted plateaus [Mohr, 1983]. South of the Turkana depression, deformation in the Kenya Rift is, similarly to the MER, characterized by large marginal fault systems, which separate a narrow rift valley (about $60-80 \mathrm{~km}$ in width) from surrounding uplifted plateaus. The MER and Kenya Rift interact within the Turkana depression, which is characterized by a style of deformation where faulting, seismicity and Quaternary-Holocene volcanic centers are widespread over a width of more than $300 \mathrm{~km}$ (Fig. 2). This testifies a wide region of ongoing rift-related tectono-magmatic activity, which is in striking contrast with the two narrow rifts to the north and south. Similarly, the Turkana region lacks the typical rift valley morphology dominated by large fault escarpments. Instead, extension is accommodated by numerous faults with limited vertical offset clustered within different sub-parallel deformation domains (Fig. 2a,d), see also Ebinger et al. [2000], where the main domains are: (i) the Turkana basin, (ii) the Kino Sogo fault belt and (iii) the Ririba Rift. The Turkana basin corresponds to the northwestward propagation of the Kenya rift via the Suguta valley, whereas the Ririba Rift (and the Hurri Hills and Marsabit volcanic lineaments) are believed to represent the southeastward propagation of the Ethiopian Rift [Ebinger et al., 2000; Bonini et al., 2005]. The Kino Sogo belt, a $30 \mathrm{~km}$-wide system of small horsts and grabens located between the Turkana basin and the Ririba Rift, accommodates a minor part of the extensional deformation [Vetel et al., 2005]. To the north, this fault system links with the Chew Bahir basin, which is part of the complex Broadly Rifted Zone of South Ethiopia [Ebinger et al., 2000; Vetel and Le Gall, 2006].

The deformation events that preceded the main Cenozoic rift phase have been suggested to have largely controlled the structural pattern and the physiography of the area, both at a regional scale [Ebinger et al., 2000; Benoit et al., 2006] and at the scale of individual faults and fault arrays [Vetel et al., 2005; Vetel and Le Gall, 2006]. In particular, the area has been affected by a significant Mesozoic rift event, which created a system of NW-SE grabens (such as the Anza graben in Ethiopia) at a high angle to the Cenozoic Ethiopian/Kenyan rift valleys (Fig. 2b). Geophysical data provide evidence for significant crustal thinning beneath the Turkana depression, where a crustal thickness $<25 \mathrm{~km}$ has been imaged (Fig. 2c) [Woldetinsae and Götze, 2005; Benoit et al., 2006; Sippel et al., 2017]. The inherited thin crust related to this Mesozoic event was suggested to cause the low topography of the region with respect to the surrounding uplifted plateaus [Benoit et al., 2006]. As a consequence, the Turkana depression is one of the few places with elevations below $1 \mathrm{~km}$ that belongs to the region of anomalously elevated topography characterizing eastern and southern Africa. 
The complex, pre-Miocene tectonic history within the Turkana depression is testified by the continuation of sedimentation in the Anza graben during the Paleogene, as well as by the roughly coeval development of N-S trending sedimentary basins (e.g., Lotikipi, Lokichar) West of Lake Turkana (Fig. 2b) [Morley et al., 1992; Morley, 1999; Ebinger et al., 2000], These basins started developing during the Oligocene-Early Miocene [Morley et al., 1992; Hendrie et al., 1994; Morley, 1999] before the beginning of Nubia-Somalia divergence and after the earliest manifestation of flood magmatism at $\sim 45 \mathrm{Ma}$ in the Broadly Rifted Zone of South Ethiopia [Davidson and Rex, 1980; George et al., 1998].

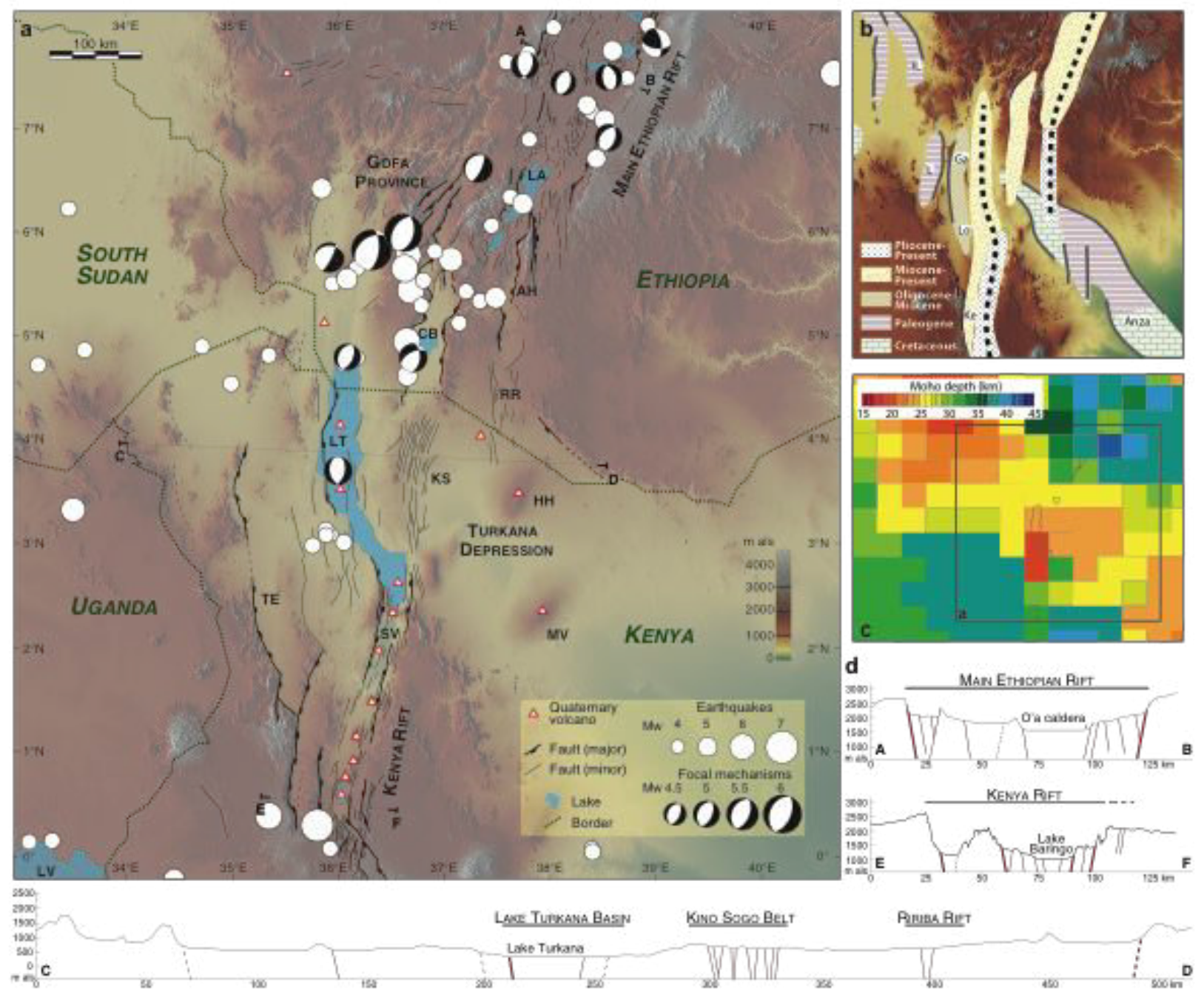

Fig. 2. Detailed tectonics of the study area. (a) Quaternary faults, seismicity and Quaternary volcanoes in the Turkana depression and surrounding regions superimposed on a SRTM (Nasa Shuttle Radar Topography Mission) digital elevation model. Seismicity from USGS National Earthquake Information Center (NEIC) catalog (1900-present); focal mechanisms from the Global Centroid-Moment-Tensor (CMT) Project; volcanoes from the Smithsonian Institution, Global Volcanism Program database. Fault pattern modified from Moore and Davidson [1978], Ebinger et al. [2000], Hautot et al. [2000], Morley et al. [2002], Vetel et al. [2005], Melnick et al. [2012], Philippon et al. [2014]. AH: Amaro Horst; CB: Chew Bahir basin; HH: Hurri Hills; KS: Kino Sogo belt; LA: Lake Abaya; LT: Lake Turkana; LV: Lake Victoria; MV: Marsabit volcano; RR: Ririba Rift; SV: Suguta Valley; TE: Turkwell Escarpment. (b) Ages of basins within the Turkana depression and simplified patterns of interaction between the Kenyan and Ethiopian rifts (black dashed lines indicate the rift axis). Basins labeled as follows: Ga, Gatome; IL, Ilubabor; Ke, Kerio; L, Lokitipi; Lo, Lokichar. Dark grey lines represent Cretaceous and Paleogene faults. (c) Map of crustal thickness in the region, from Benoit et al. [2006]. (d) Simplified cross-sections highlighting the different style and distribution of deformation in the Turkana depression with respect to the Kenyan and Ethiopian Rifts. 
During Early Miocene times, extension started in the Chew Bahir basin, contemporaneous with a first, minor phase of extensional deformation in the Southern MER [Bonini et al., 2005; Pik et al., 2008]. Basin development began in the Lake Turkana region at around $15 \mathrm{Ma}$, followed by activation of large boundary faults at around $12 \mathrm{Ma}$ in the Broadly Rifted Zone of South Ethiopia and at 8-10 Ma in the Amaro Horst region of the Southern MER [Balestrieri et al., 2016]. During the Pliocene-Quaternary, the volcanotectonic activity focused in the Lake Turkana basin, now a direct continuation of the Kenya Rift, whereas the extensional deformation related to the MER propagated southward into the Eastern Turkana depression (Ririba Rift, Hurri Hills and Marsabit volcanic lineaments) [Bonini et al., 2005].

Overall, a progressive eastward migration of Oligocene-recent deformation within the Turkana depression has been suggested [Ebinger et al., 2000 and references therein] [Ebinger et al., 2000 and references therein]. This migration, together with a northward propagation of rifting in the Kenya rift and a southward propagation of the Main Ethiopian rift to the Ririba and Marsabit volcanic lineaments, is considered responsible for the anomalous breadth of the zone of deformation in the region [Ebinger et al., 2000]. Strain hardening between episodes of extension [Morley et al., 1992] or deep-seated asthenospheric processes such as plume impingement at the base of the lithosphere [Ebinger et al., 2000] have been considered responsible for the progressive eastward migration in the Turkana depression.

\section{Initial and boundary conditions for modeling}

We conduct both analog and numerical experiments in order to investigate the interaction between the Ethiopian and Kenyan rifts across the Turkana depression. These modeling approaches complement each other since analog models are powerful in analyzing brittle deformation and the surface fault pattern at a very high resolution (here: $\sim 800 \mathrm{~m}$ ), but are limited in that they normally cannot account for complex rheologies and thermal variations during deformation and related processes. These complexities are instead well reproduced and analyzed in numerical models, which however are more limited in accounting for brittle deformation and in model resolution (here: $7 \mathrm{~km}$ ). In the following we outline the general model framework, while the specific setup for analog and numerical models is discussed in Sections 4 and 5, respectively.

We capture the first-order regional plate tectonic setup by subdividing the region into three different domains, namely: Turkana depression, Kenya/Ethiopia rifts, and plateaus outside of any rift (Fig. 3). The main starting point for our modeling is the presence of thin crust beneath the NW-SE trending domain of Mesozoic extension (Section 2). We set the initial crustal thickness in this area to $30 \mathrm{~km}$, which represents the initial Moho depth before the onset of Neogene rifting. This value corresponds to the thickness of crystalline crust within parts of the Anza graben that have not been reactivated [Fig. 2c; see also Benoit et al., 2006; Sippel et al., 2017]. The stable plateaus and the rift valleys are characterized instead by an initial thickness of about $40 \mathrm{~km}$, which is the average Moho depth of today's plateaus in both domains [Keranen et al., 2009; Sippel et al., 2017]. For the thickness of the felsic upper crustal layer at the onset of Neogene rifting we use a value of $20 \mathrm{~km}$. This is justified through Kenyan and Ethiopian seismic refraction surveys that exhibit $v_{p}$ larger than $6.5 \mathrm{~km} / \mathrm{s}$ at depths of $20 \mathrm{~km}$ alongside the main grabens [Keller et al., 1994; Maguire et al., 2006]. These velocities further indicate that the lower crust is composed of mafic lithologies [Christensen and Mooney, 1995]. We have also assumed a 
strength contrast between plateaus and Turkana depression and Kenyan/Ethiopian rift valleys. Both domains have been likely influenced by channeling and ponding of plume material in the Oligocene/Miocene [Ebinger and Sleep, 1998; Ebinger et al., 2000], resulting in an elevated lithosphere-asthenosphere boundary (LAB) with respect to the surrounding plateaus. In the numerical models this is represented directly through different thermal LAB depths in each domain, while in the analog model we implement the strength contrast through different materials and layer thicknesses.

According to recent geodetical estimates [Saria et al., 2014; Stamps et al., 2014], extension in the models has been considered to be orthogonal to the Ethiopian/Kenyan rift valleys, i.e., roughly E-W (Fig. 1). Note that our models are focused on the Eastern Branch of the EAR, and do not consider the transfer of deformation from the latter to the Western Branch. The amount of total extension, the velocity of plate motion in the past, and the timing of initiation of Nubia-Somalia motion are not well constrained, as different plate motion models predict different values. Plate tectonic models that integrate sea-floor spreading reconstructions into plate circuits indicate that divergence between the major plates started before $16 \mathrm{Ma}$ [DeMets and Merkouriev, 2016], likely at $20 \mathrm{Ma}$ [Iaffaldano et al., 2014], with maximum values of extension of approximately $80 \mathrm{~km}$ [laffaldano et al., 2014]. Geological data, however, seems to point to a later rift activation (at 10-12 Ma; see Balestrieri et al. [2016] and references therein) and lower amount of total extension ( 30$40 \mathrm{~km}$; Corti [2009] and references therein). In this study we incorporated 15 My of symmetric extension at rates of $\sim 4 \mathrm{~mm} / \mathrm{yr}$, resulting in a total amount of extension of 60 $\mathrm{km}$.

\section{Analog modeling}

\subsection{Model setup}

The analog models were performed in an artificial gravity field of $\sim 18 \mathrm{~g}$ using the largecapacity centrifuge available at the Tectonic Modelling Laboratory of the Institute of Geosciences and Earth Resources (National Research Council of Italy) and the Department of Earth-Sciences of the University of Florence. The models simulated a simplified rheological layering composed of brittle-ductile crust floating above a low viscosity material (Fig. 3). The use of the centrifuge technique to perform experiments is based on the principle that the centrifugal force plays the same role in the models as does the force of gravity in natural geologic processes [Ramberg, 1981]. In the centrifuge, the models thin vertically and expand laterally in response to the centrifugal body force field that act during a centrifuge run. More specifically, the models, with dimensions of $16 \times 16 \times 1.5 \mathrm{~cm}$, were built inside a rectangular Plexiglas box and were laterally confined by rectangular blocks (spacers) that were removed before running the model for a given time interval in the centrifuge (Fig. 3a). During the centrifuge run, the models expanded to fill the empty space at their sides, simulating extensional tectonics in nature; sequential removal of spacers during successive runs in the centrifuge allowed controlling the amount and rate of extension. Top-view photos and laser scans of the models were taken after the end of each centrifuge run in order to monitor the evolution of surface deformation. The models were frozen before taking a number of cross sections to study their internal geometry. This modeling technique has been extensively tested and employed in different settings (see for instance Ramberg [1981]; Corti et al. [2003]; Corti [2012]). 


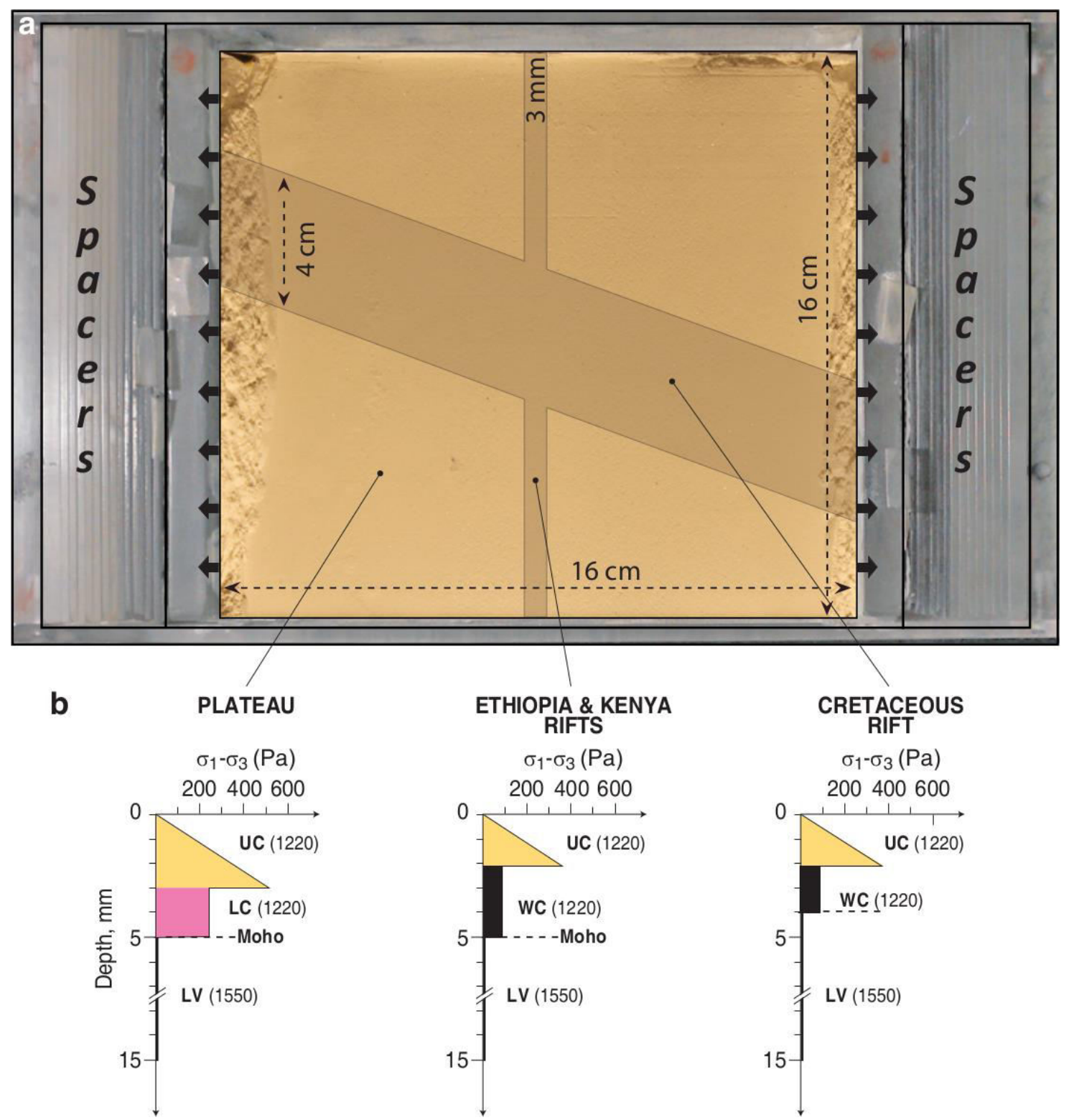

Fig. 3. Analog modeling setup. (a) Top-view of the experimental apparatus (see text for details). (b) Strength profiles in the different model domains. LC: lower crust; LV: low viscosity mixture providing isostatic support to the overlying crust; UC: upper crust; WC: weak lower crust.

\subsection{Rheological layering, materials and geometry}

The two-layer models are composed of an upper brittle layer simulating the upper crust that, as in several previous centrifuge experiments [e.g. Agostini et al., 2009; Corti, 2012], was modeled by using a K-feldspar powder characterized by a linear increase in strength with depth to reproduce natural brittle behavior (Fig. 3b). The underlying ductile lower crust in the plateau domains was modeled with a mixture of plasticine (Pongo Fantasia modeling dough, distributed by FILA) and PDMS-Polydimethylsiloxane (Dow Corning, SGM36), with proportions of 100:80\% in weight. The lower crust beneath the rift valleys and the Turkana domain was reproduced by using a similar weak mixture of silicone (Dow Corning DC3179), corundum sand and oleic acid (100:20:5\% in weight). The models involved a thinner crust beneath the Turkana depression with respect to the surrounding domains. Considering the absence of the underlying lithospheric mantle, this makes the Turkana depression slightly weaker than the Ethiopia/Kenya rifts. However, we tested other conditions in which the Turkana domain had the same strength or was 
a

Extension $4 \mathrm{~mm}(32 \mathrm{~km})$

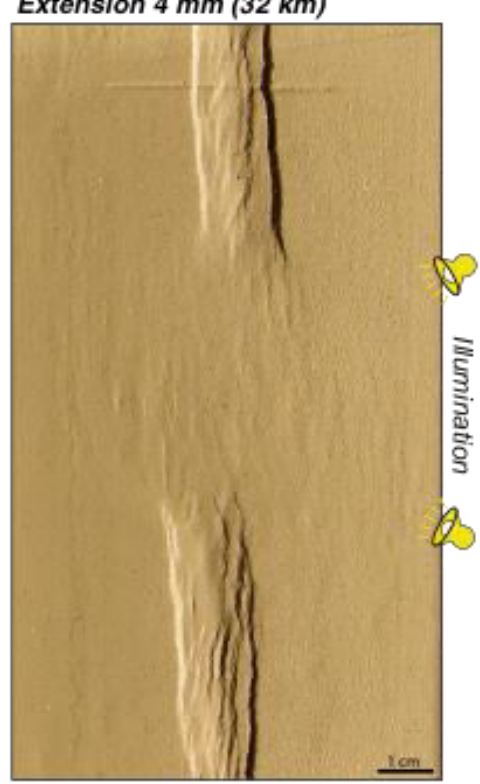

Extension $8 \mathrm{~mm}(64 \mathrm{~km})$

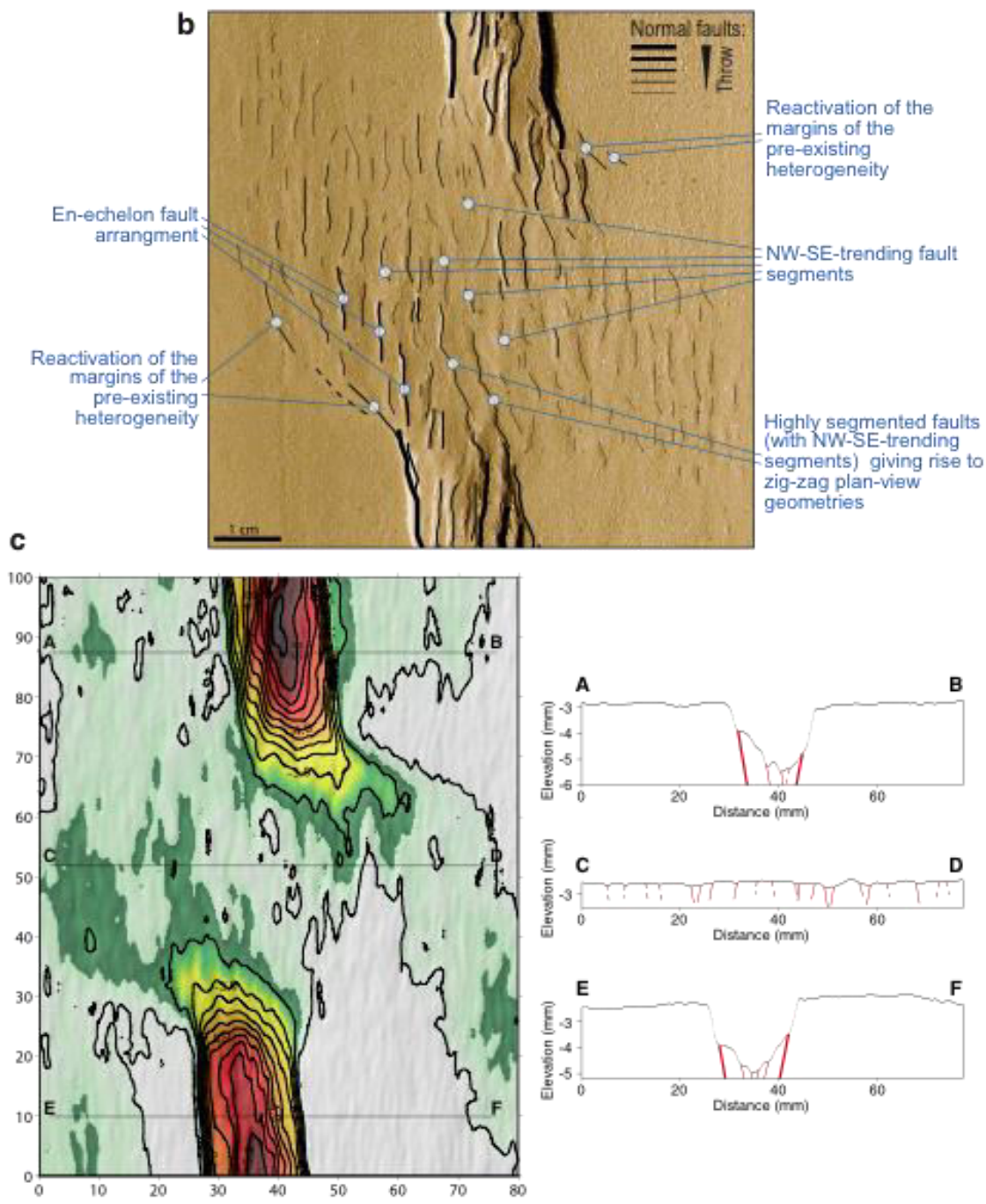

Fig. 4. Analog modeling results. (a) Top-view photos of the analog model for $4 \mathrm{~mm}$ and $8 \mathrm{~mm}$ bulk extension. (b) Line drawing of structures with examples of deformation features affecting the central part of the model. (c) Digital elevation model of the surface and topographic profiles at the end of deformation (8 $\mathrm{mm}$ bulk extension). 
slightly stronger than the rifts (see below and Supplementary Figure S1). All these crustal layers rested on a low viscosity mixture of DC3179, corundum sand and oleic acid (100:80:15\% in weight), which provided isostatic support to the extending, overlying crust (Fig. 3).

The geometry of the models mimicked that of the natural prototype at a scale of $\sim 1.3 \times 10^{-7}$, such that $1 \mathrm{~cm}$ in the experiments corresponded to $\sim 80 \mathrm{~km}$ in nature. This allowed modeling $\sim 60 \mathrm{~km}$ of total extension. Dynamic-kinematic similarity of gravitational, viscous and frictional stresses acting in the system [Ramberg, 1981] ensured that the velocity of lateral displacement in the models $\sim 2.5 \times 10^{-5} \mathrm{~m} / \mathrm{s}$ scaled to natural values of $\sim 3-5 \mathrm{~mm} / \mathrm{yr}$.

\subsection{Analog modeling results}

Upon extension, deformation localized within the rift domains, giving rise to major fault escarpments bounding a subsiding narrow depression (Fig. 4). These major faults formed at the rift/plateau boundaries, whereas systems of internal normal faults with more limited vertical displacement affected the rift floor. In both Kenyan/Ethiopian rift domains, deformation was entirely localized within the narrow depressions, i.e. in an area, which was $\sim 1.4 \mathrm{~cm}(\sim 110 \mathrm{~km})$ wide after $4 \mathrm{~mm}(\sim 30 \mathrm{~km})$ of bulk extension (Fig. 4a). The Turkana domain was instead characterized by a much wider region affected by deformation (up to $\sim 7 \mathrm{~cm}$ - i.e., $\sim 550 \mathrm{~km}$ - in width). Within this region, extension was accommodated by a much higher number of normal faults characterized by a limited vertical displacement and a general N-S trend.

During progressive extension, this overall architecture did not change significantly. Owing to an increase in slip on the boundary fault systems, the rift depression progressively increased its subsidence; the width of the rift valley increased to $\sim 1.8 \mathrm{~cm}$ $(\sim 140 \mathrm{~km})$, indicating that extension was entirely accommodated within it. In contrast, deformation within the Turkana depression was still distributed over a wide region $(\sim 8 \mathrm{~cm}$ - i.e., $\sim 640 \mathrm{~km}$ - in width) and accommodated by a large number of small-offset normal faults (Fig. 4). These faults were locally characterized by a zig-zag pattern and by a trend that - although generally N-S - displayed local deviations to a more NNW-SSE orientation. Reactivation of the NW-SE-trending boundary between the weak Turkana depression and the strong surrounding plateaus occurred locally, as observed at the NW termination of the Kenyan rift valley (Fig. 4).

Observation of the fault pattern and the topography of the model surface at the end of deformation (Fig. 4b) indicates that, entering the Turkana domain, the region of maximum subsidence (i.e., highest fault activity) related to the Ethiopian domain propagated towards the SE whereas that of the Kenyan domain propagated towards the NW. Instead of linking directly to form a throughgoing N-S depression, the rift valleys propagated away from each other within the Turkana depression giving rise to a right-lateral stepover of interacting rifts.

In different models we have tested different rheologies for the Turkana domain, rendering it slightly stronger or characterized by a similar strength with respect to the Kenyan/Ethiopian Rifts. The model results are at a first order similar to the one described above in terms of distribution and characteristics of deformation (see Supplementary Figure S1), underlining the robustness of our results. 


\section{Numerical modeling}

In addition to the analog experiments presented in Section 4, the numerical model captures also the thermal evolution of the system taking into account radiogenic heating of the crust and thermal equilibration of the lithosphere. Hence, the brittle layer thickness and thus the degree of crust-mantle coupling is a dynamically evolving component of the model.
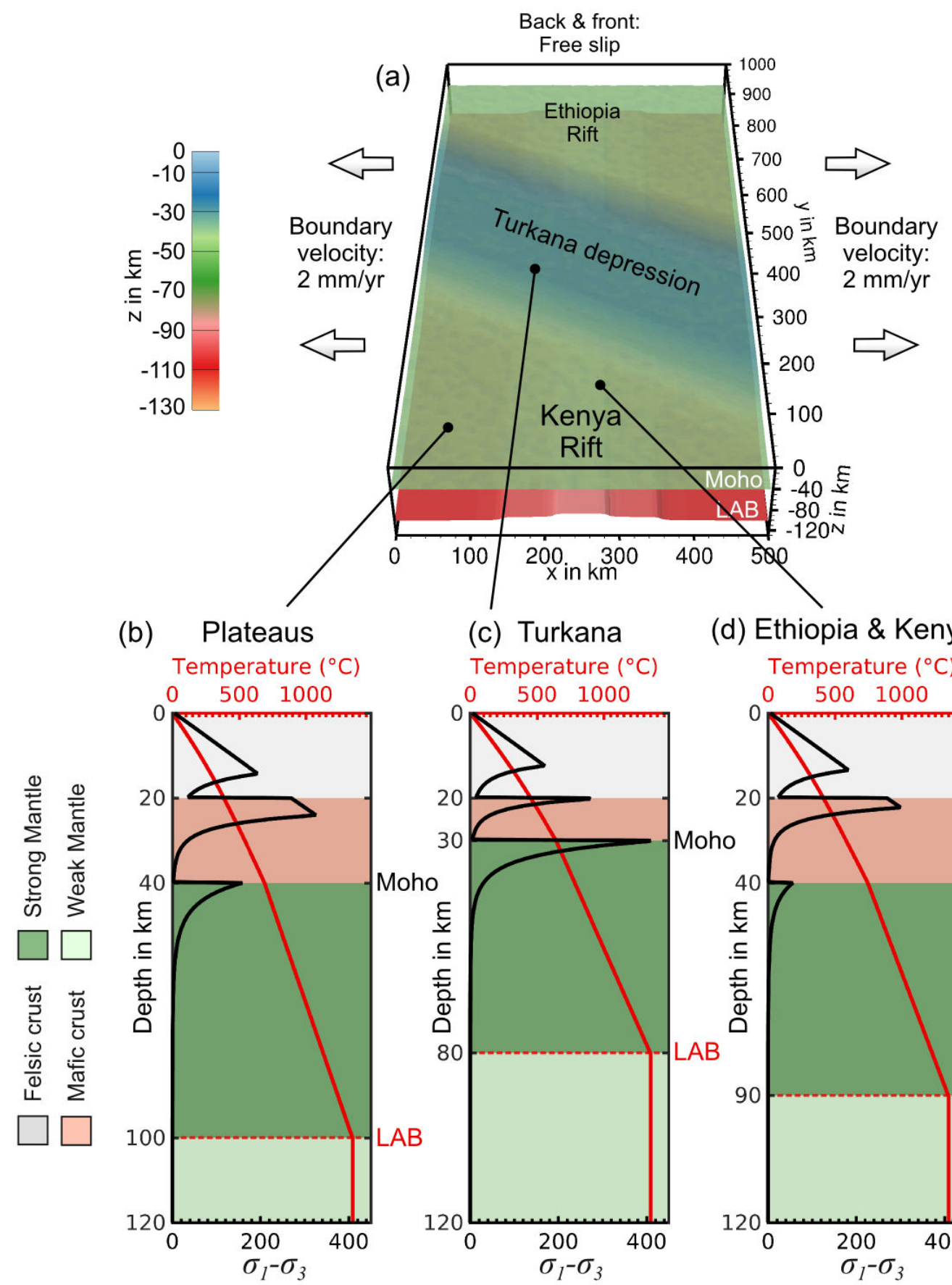

(c) Turkana

Temperature $\left({ }^{\circ} \mathrm{C}\right)$

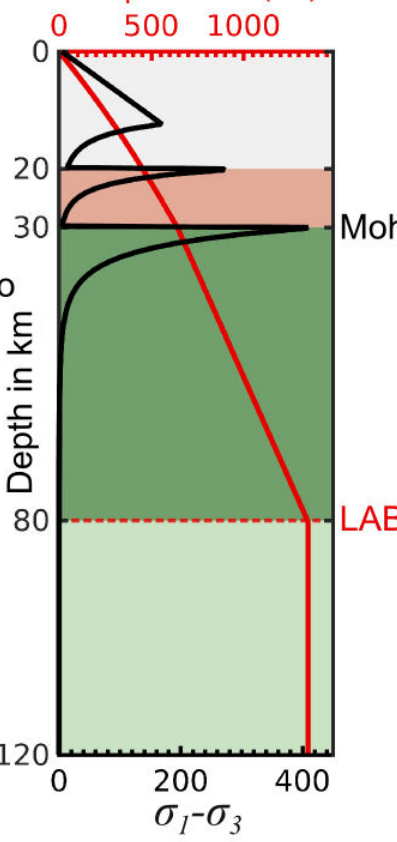

(d) Ethiopia \& Kenya Rifts

Temperature $\left({ }^{\circ} \mathrm{C}\right)$

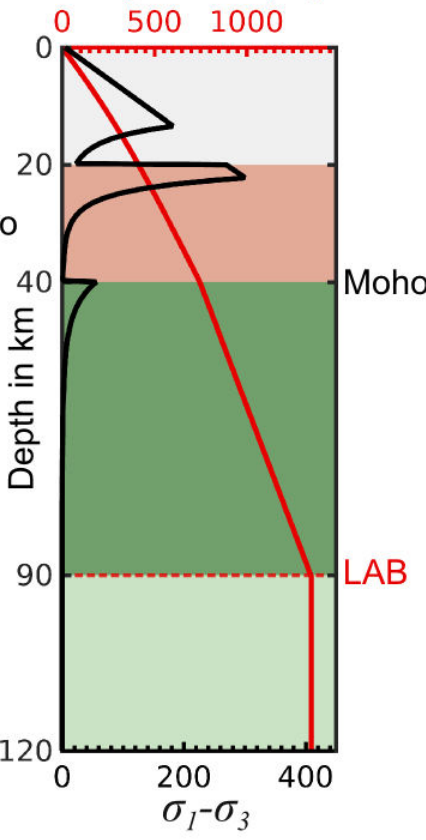

Fig. 5. Numerical model setup. (a) Boundary conditions and domain locations (b-d) Thermal profile and yield strength profiles computed for the initial bulk extension rate of the models, i.e. $2.7 \cdot 10^{-16} 1 / \mathrm{s}$. For numerical parameters see Supplementary Table 1. 


\subsection{Model setup}

In the following we apply the finite element code SLIM3D [Popov and Sobolev, 2008], which solves the conservation equations of momentum, energy and mass using an Arbitrary Lagrangian-Eulerian formulation involving the particle-in-cell technique. The deformation of materials is accommodated via an elasto-visco-plastic rheology, which self-consistently reproduces diverse deformation processes like faulting, flexure and lower crustal flow. SLIM3D has been extensively benchmarked and applied to model lithospheric-scale processes in divergent [Brune et al., 2012, 2013; Brune and Autin, 2013; Brune, 2014; Heine and Brune, 2014; Koopmann et al., 2014; Clift et al., 2015; Brune et al., 2016, 2017], convergent [Quinteros et al., 2010; Quinteros and Sobolev, 2012; Duesterhoeft et al., 2014] and transform [Popov et al., 2012; Brune, 2014] plate boundaries as well as in a centimeter-scale study of localization dynamics [Cyprych et al., 2016].

The model has a free surface at the top boundary, while at the bottom boundary we apply an isostatic Winkler boundary condition, where in- and outflow of material is accounted for during re-meshing. We use a constant rift velocity of $4 \mathrm{~mm} / \mathrm{yr}$ (full rate) so that a $2 \mathrm{~mm} / \mathrm{yr}$ velocity is prescribed orthogonal to both model boundaries facing in $x-$ direction (Fig. 5). Front and back boundaries feature free slip. The numerical model comprises a domain of $500 \times 1000 \times 130 \mathrm{~km}$ in $x$ (cross-rift), $y$ (along-strike) and $z$ direction (depth) and a resolution of $\sim 7 \mathrm{~km}$ in all directions.

Temperature boundary conditions are as follows: the surface temperature is held constant at $0^{\circ} \mathrm{C}$, and the bottom temperature at $1350{ }^{\circ} \mathrm{C}$. Lateral boundaries are thermally isolated. At the model start, the temperature field results from the thermal equilibrium governed by the boundary conditions, the crustal radiogenic heat contribution and by the initial depth of the $L A B$, defined through the $1300^{\circ} \mathrm{C}$ potential temperature isotherm, which locates at $100 \mathrm{~km}$ depth under the plateaus, $80 \mathrm{~km}$ depth beneath the Turkana depression and $90 \mathrm{~km}$ depth beneath the Ethiopia and Kenya rifts (Fig. 5) unless otherwise indicated. The slightly shallower LAB beneath the rifts is used to seed strain localization without imposing crustal fault locations. Note that due to radiogenic heat production, domains with thin crust generate less heat than those with thick crust. For simplicity, we focus on lithospheric processes and do not implement heterogeneities in the deeper parts of the mantle such as the Afar plume [Ebinger and Sleep, 1998; Hansen and Nyblade, 2013] or the northward shallowing of the LAB under East Africa [Fishwick and Bastow, 2011].

The model accounts for four material layers: felsic crust, mafic crust, strong mantle and weak mantle (Fig. 5b). For the quartz-dominated felsic upper crust, we use the wet quartzite flow law of Gleason and Tullis [1995]. The mafic lower crustal layer is represented by a wet anorthite flow law [Rybacki and Dresen, 2000]. We use dry olivine rheology [Hirth and Kohlstedt, 2003] to model deformation of the strong, depleted, subcontinental mantle, while a wet (i.e., $1000 \mathrm{ppm} \mathrm{H/Si}$ ) olivine flow law [Hirth and Kohlstedt, 2003] is applied for the weak, asthenospheric mantle. All rheological parameters are listed in Supplementary Table 1. The model involves linearized frictional strain softening, a standard strategy to parameterize fault weakening [Bos and Spiers, 2002] in numerical models [Huismans and Beaumont, 2011; Naliboff and Buiter, 2015; Le Pourhiet et al., 2017]. Here we linearly reduce the friction coefficient from 0.5 to 0.05 for brittle strain between 0 and 0.5 . For strains larger than 0.5 , it remains constant at 0.05 . Similarly we reproduce viscous strain softening [Bürgmann and Dresen, 2008] by 
increasing the pre-exponential factor of the ductile flow law by 10 times between viscous strains 0 and 0.5 , which results in a moderate viscosity reduction of $\sim 0.5$.

\subsection{Numerical modeling results}

In numerical model $\mathrm{A} 1$ the rift exhibits a distinct northern, central and southern segment (Fig. 6a-c). After 5 My model time, high tectonic strain rates of more than $10^{-15}$ $1 / \mathrm{s}$ are encountered in the northern and southern segment in a narrow band of roughly $100 \mathrm{~km}$ width. At the transition to the central segment, the rift arms bend away leftlaterally from the transversal central region, giving rise to a right-lateral stepover geometry. Simultaneously the rifts connect with each other such that the lateral extent of the rift in the central domain increases almost to the entire model width of $500 \mathrm{~km}$. During subsequent model evolution, the northern and southern segments localize towards the basin center finally reaching a width of $\sim 70 \mathrm{~km}$ at 15 My model time, while the N-S trending deformation domains inside the central segment are distributed with a width of about $300 \mathrm{~km}$.

Next we focus on the final structure of the model after $15 \mathrm{My}$ model time. The northern and southern rifts feature a deep basin of up to $100 \mathrm{~km}$ width (Fig. 6g), whereas the central domain consists of a wide plain with N-S oriented horst and grabens and relatively low relief. The final topographic pattern primarily results from the isostatic response to crustal thinning, which is why surface topography mirrors Moho depth (Fig. 6f) except for local horsts and grabens. Both topography and Moho depth exhibit left-lateral bending where the north/south rifts merge into the central domain. However the LAB topography does not show this pattern indicating the lateral strength contrast in the shallow lithosphere as the main control for this pattern. The surface velocity field clearly shows the transition from narrow to wide rifting in the $x$-component of velocity (Fig. $6 \mathrm{i})$. The rightlateral stepover from the northern to the southern segments creates a specific tectonic strain field that leads to northward velocities in the eastern part of the Mesozoic rift basin and southward movement in its western part (Fig. 6j) predicting minor counterclockwise rotation of the central domain. These velocities of less than $0.4 \mathrm{~mm} / \mathrm{yr}$ are a magnitude smaller than the overall extension velocity and do not generate any indication of strikeslip deformation. However, the direction of motion compares well with observations and models of other extensional plate boundaries with stepover geometries, such as in the western branch of the EAR [Koehn et al., 2008].

In the previous analog and numerical models we find a left-lateral bend (resulting in a right-lateral stepover) of the narrow rifts at the transition to the transversal central domain. In the following we investigate the rheological configurations that enable this type of rift connectivity. To this aim we modify layer thicknesses and thereby the thermal profile within the inherited Mesozoic rift (see Supplementary Table 2) while the other model domains remain unchanged. Note that the thicknesses of crust and mantle at the onset of Cenozoic rifting cannot be deduced directly. Hence, we define a range of plausible layer thicknesses for the Turkana region by considering those parts of the Mesozoic African rift systems that have not been reactivated. One such example is the Anza graben in northeast Kenya with 25 to $30 \mathrm{~km}$ thick crust [Sippel et al., 2017], and a lithosphere thickness of 60 to $90 \mathrm{~km}$ [Fishwick, 2010]. Similar thicknesses have also been found in the Central and West African Rift System for both lithospheric [Fishwick and Bastow, 2011] and crustal [Pasyanos et al., 2014] layers. 
Model A1 - Reference Model Turkana
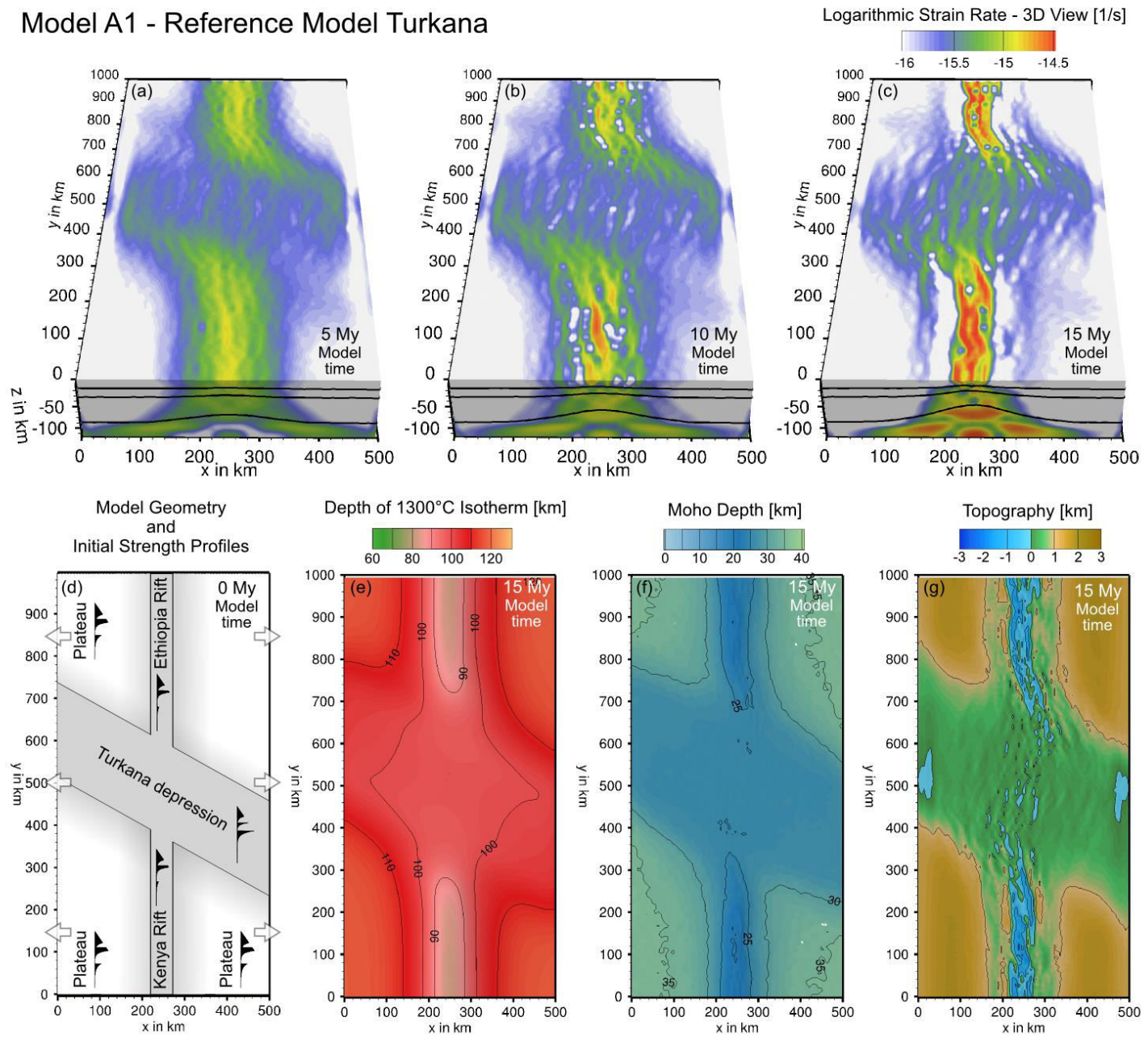

Logarithmic Strain Rate [1/s]

$$
\begin{gathered}
\text { Velocity (x-component) } \\
{[\mathrm{mm} / \mathrm{yr}]}
\end{gathered}
$$
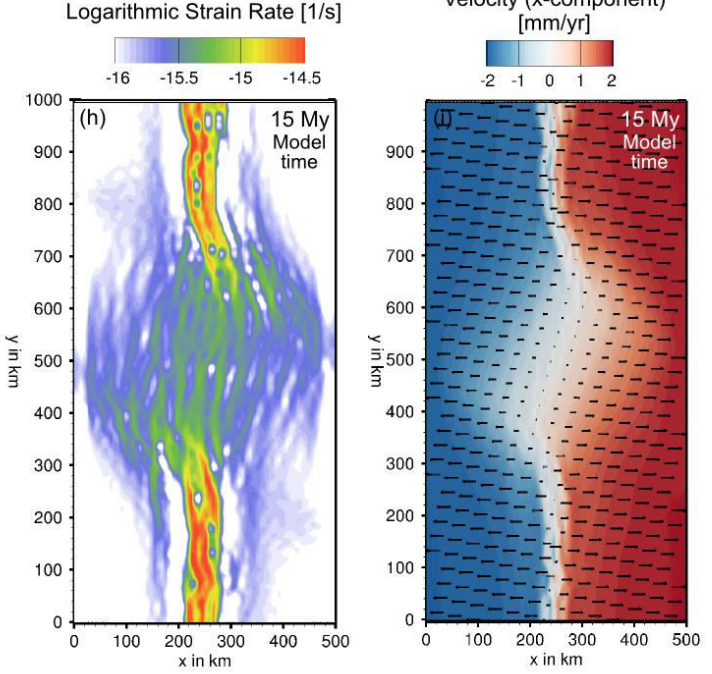

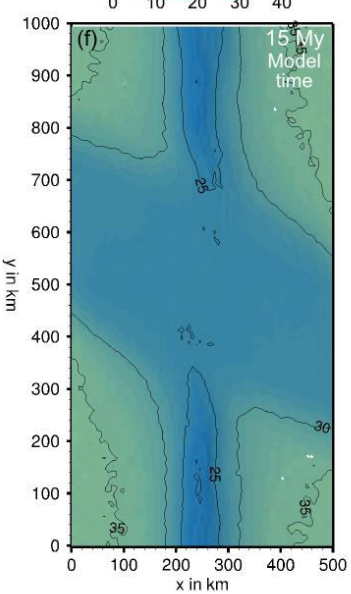
[mm/yr]

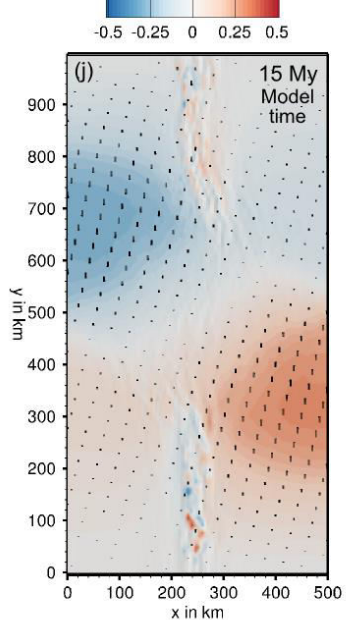

Velocity (y-component)

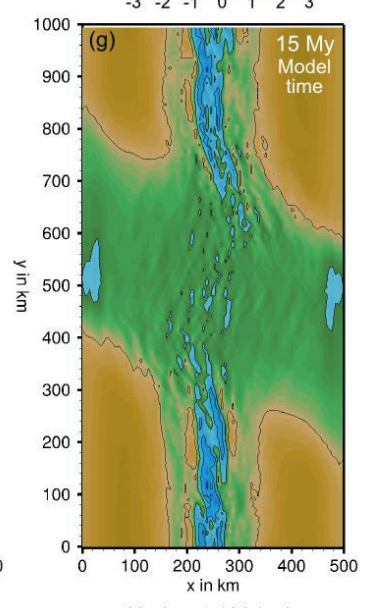

Horizontal Velocity [mm/yr]

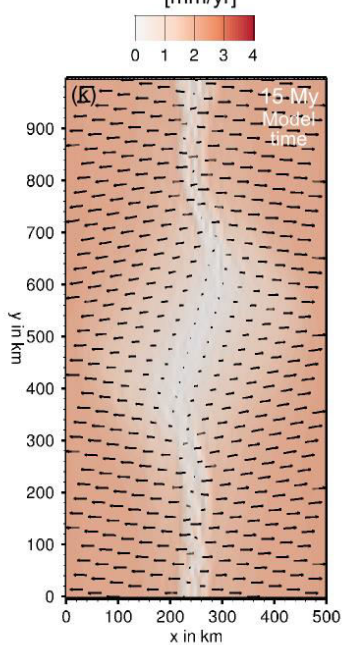

Fig. 6. Numerical reference model. (a-c) Evolution of deformation pattern (second invariant of strain rate) in $3 D$ view. Numerical simulations at $15 \mathrm{My}$ are comparable to the present-day structure of the study region. Note the left-bending rift tips (and thus right-stepping rift segments) where the northern and southern rifts interact with the central domain. (d) Initial model geometry in map view. (e) Final lithosphereasthenosphere boundary (LAB). (f) Final Moho depth. (g) Final surface topography. (h) Final deformation pattern in map view. (i,j) N-S and E-W directed components of surface velocity. (k) Full horizontal velocity field. See supplementary animations A1 for detailed model evolution. 
(a)

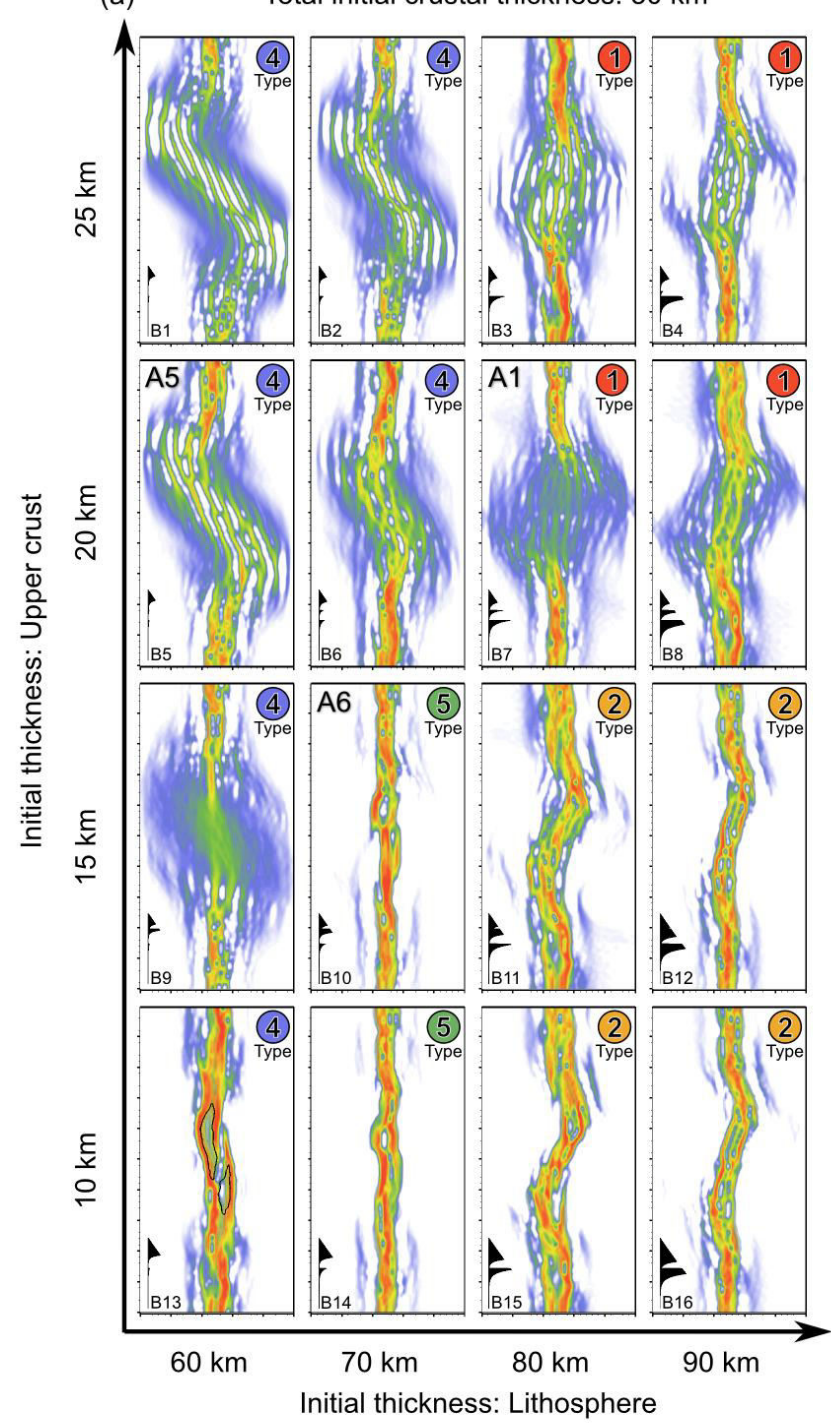

(b) Total initial crustal thickness: $25 \mathrm{~km}$

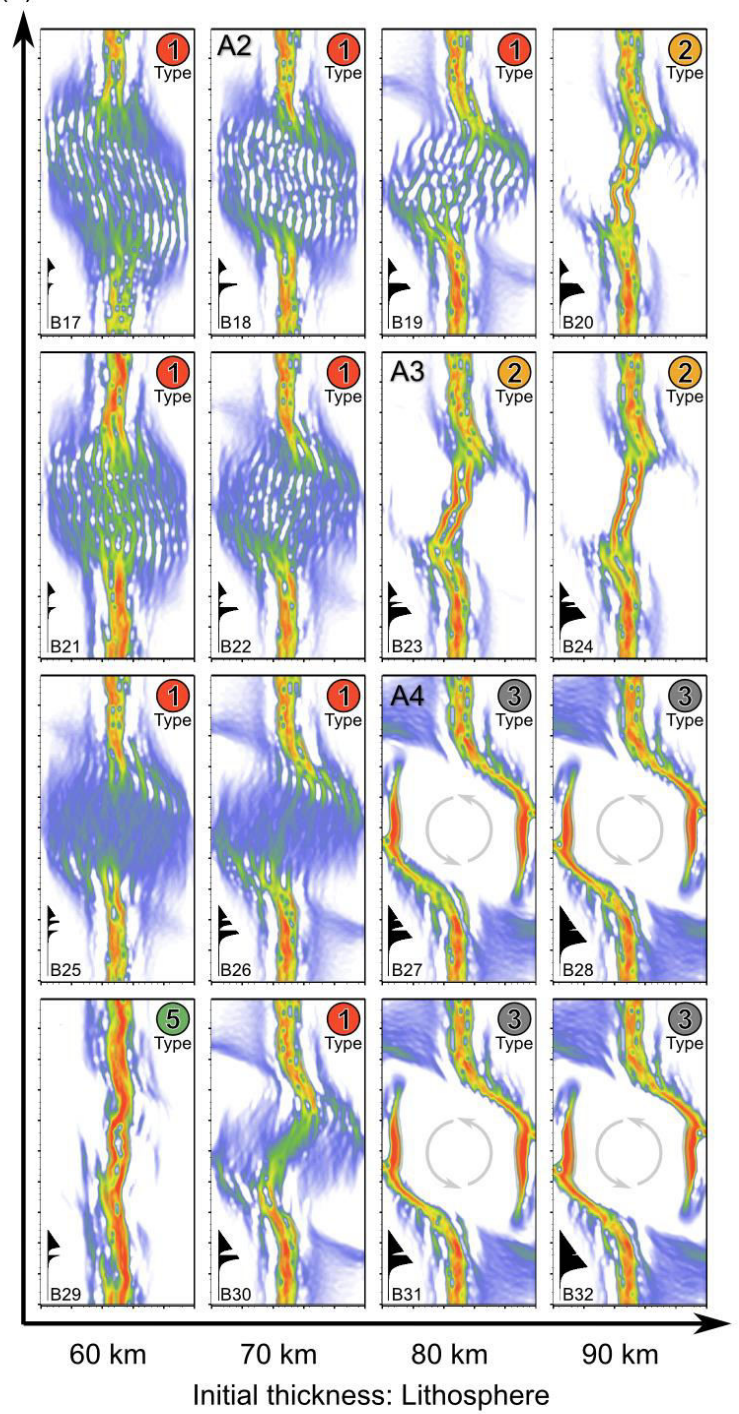

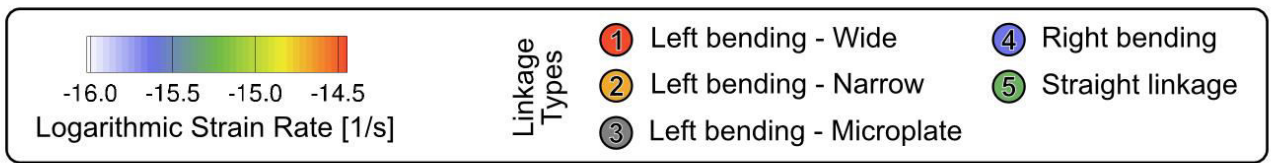

Fig. 7. Alternative model results. We vary the initial conditions by scanning through different configuration of initial thicknesses of lithosphere, full crust, and upper crust within the transverse inherited domain of the Turkana region. (a) Initial crustal thickness of $30 \mathrm{~km}$. (b) Initial crustal thickness of $25 \mathrm{~km}$. All other parameters and layer thicknesses are kept identical to model A1. Images show strain rate patterns after $15 \mathrm{My}$ of stretching, equivalent to $60 \mathrm{~km}$ of extension. In the lower left corner of each image we plot the yield strength profile of the transverse central region at the onset of rifting. Lithospheric strength is controlled by the interplay of lithospheric thickness and radiogenic heat production within the upper crust. The initial strength controls rift localization and leads to 5 different types of rift linkage after $15 \mathrm{My}$ indicated in the upper right corner of each image. Initial strength of each layer within the central domain of all models is also provided in Supplementary Table 2. Animations of six characteristic models representing key aspects of rift linkage are given in the supplementary material as animations A1 to A6 (upper left corner). 
The resulting deformation patterns after 15 My model time are depicted along with initial vertical strength profiles of the central transversal domain in Fig. 7. We find a large variety of rift patterns that are solely due to the rheological configuration of the central domain. The patterns can be classified into five distinct types: a group of three left-lateral bending types (i.e. right-stepping rift segments) where rifting in the central domain occurs (1) as a wide rift like in the Turkana region and as in model A1, (2) in narrow rift mode, (3) through microplate formation. Further we identify (4) a right-lateral bending type and (5) a type with straight segment linkage. Representative model animations for the evolution of each linkage type can be found in the supplementary materials.

The existence of these 5 types can be explained at first-order by considering the strength contrast between crust and mantle in each model (Fig. 8). In most cases where the strength of the mantle in the central domain is larger than that of the plateaus outside of the rift zones, the northern and southern segment avoid a direct connection by forming the left-lateral bend near the central segment (Type 1, 2, and 3). Hence, the left-lateral bend results from minimizing the mechanical work that is required to deform the central domain. This further indicates that mantle strength exerts first-order control on surficial
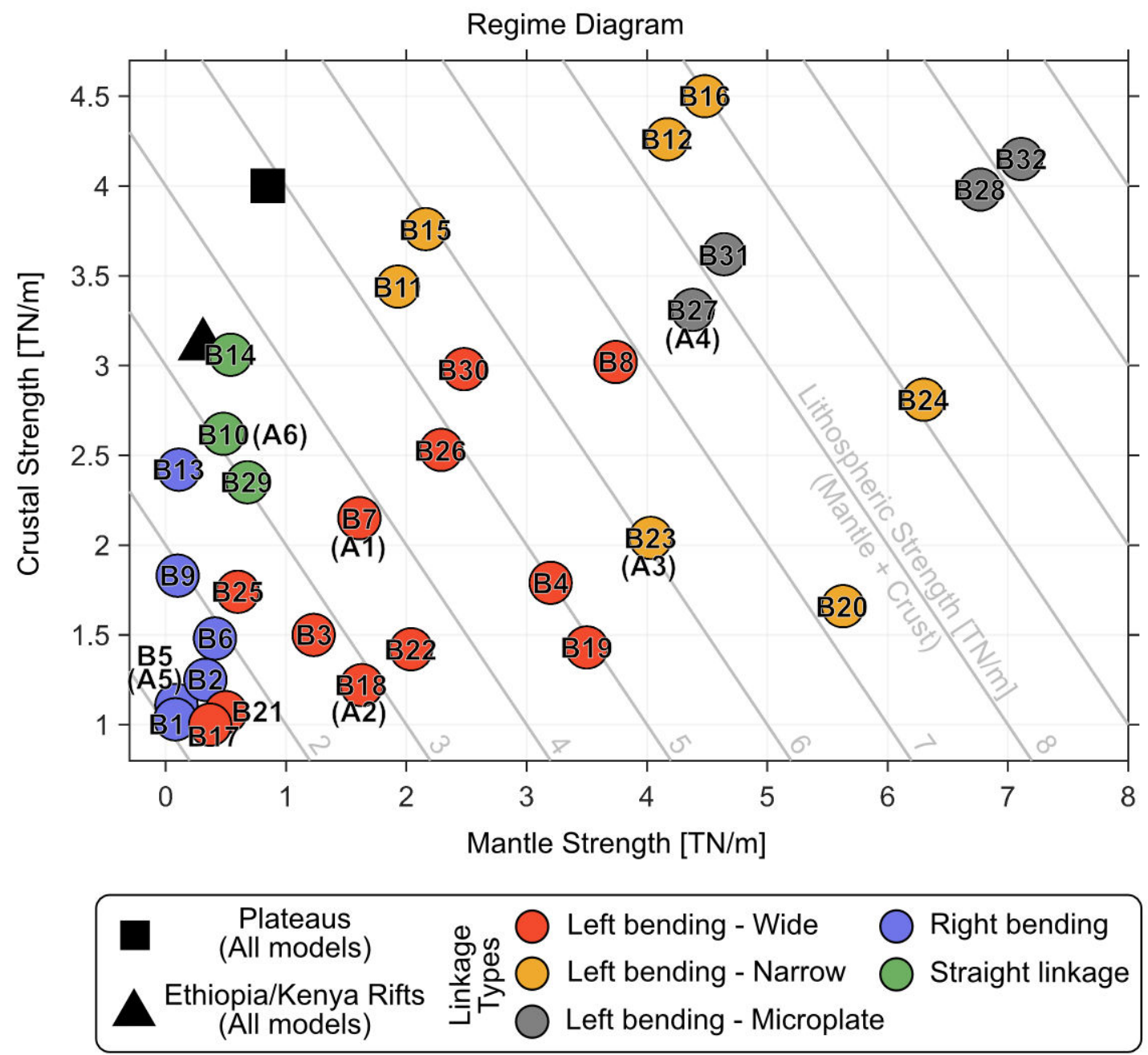

Fig. 8. Regime diagram. All models of Fig. 7 are represented in terms of initial crustal and mantle strength within the Turkana depression. Initial strength of other model domains such as plateaus, and Ethiopia/Kenya rifts are shown as black square and triangle, respectively. The 5 linkage types are identified by colored circles. Gray, diagonal lines indicate total lithospheric strength. For characteristic models A1 to A6 we provide supplementary animations of the model evolution. 
deformation pattern by controlling the location of lithospheric necking. Wide rifting (Type 1) dominates for integrated lithospheric strengths below $\sim 4-6 \mathrm{TN} / \mathrm{m}$ (gray diagonal lines in Fig. 6c), while narrow rifting (Type 2) and microplate formation (Type 3) prevails for higher lithospheric strengths. This can be understood when considering that in this highstrength regime brittle deformation leads to more rapid localization so that lithospheric necking occurs faster which promotes narrow rifting. In fact, left-bending wide rifts (Type 1) eventually localize into narrow rifts (Type 2) while the initial stages of narrow rifts (Type 2) feature wide rift characteristics (see Supplementary Animations A1-A3), hence the difference between these types is time-dependent. Microplate formation occurs for highstrength end-members within the left bending regime. In these scenarios, the central domain behaves like an almost undeformable block that diverts strain to the lateral model boundaries. In agreement with continental and oceanic microplate rotations, the rightlateral stepover geometry generates a counter-clockwise rotating microplate [Katz et al., 2005; Koehn et al., 2008]. Right-lateral bending (i.e. left-stepping) of the northern and southern rifts (Type 4) occurs if the mantle strength in the central domain is less or similar to that of these segments. In this case the mantle beneath the central rift is so weak that it governs the necking process and forces crustal localization to bend right-laterally into the central segment. This case is reminiscent to recent analog models of propagating rotational rifts interacting with linear rheological heterogeneities cutting the rift at moderate and high obliquity [Molnar et al., 2017]. If the rheological configuration of the central domain is very similar to the rift valleys to the north and south, the model virtually does not notice the inherited heterogeneity and straight linkage (Type 5) occurs. While these explanations hold at first order, the strength diagram also shows that the transition from one regime to the other does not occur as an abrupt boundary.

\subsection{Model limitations and robustness}

The numerical model includes only the lithosphere and shallow asthenosphere, hence it does not account for mantle-related topographic changes caused by asthenospheric flow [Emishaw et al., 2017], small-scale convection [van Wijk et al., 2008] or wholemantle convection [Flament et al., 2013; Rubey et al., 2017]. These dynamic topography contributions add to the isostatically compensated topography, especially above regions of focused upwelling. For the Ethiopian dome, independent studies attributed amplitudes of $\sim 1.5 \mathrm{~km}$ to this kind of dynamic mantle support [Hoggard et al., 2016; Sembroni et al., 2016], which is why we chose this value for our initial topographic baseline.

When comparing numerical results to regional geophysical models of Moho and LAB depth one has to keep in mind that our numerical model locally conserves crustal mass. This means we do not account for magmatic underplating or basin sedimentation leading to replenishment of crustal thickness. The contributions of these processes to crustal rethickening beneath EAR rift valleys are up to $3 \mathrm{~km}$ for sedimentation [Ebinger et al., 1999; Sippel et al., 2017] and about 4 km for underplating in the Kenya Rift [Thybo et al., 2000].

Values of experimentally determined creep parameters for the chosen compositions vary slightly in the literature. We therefore tested the influence of alternative flow laws for upper crust [Rutter and Brodie, 2004], lower crust [Rybacki et al., 2006] and mantle [Karato and Jung, 2003] and found that despite minor structural differences our conclusions were robustly reproduced. The model results did not change when we simultaneously applied dislocation and diffusion creep within the mantle [Hirth and Kohlstedt, 2003] instead of only dislocation creep as in the models above. We used $1 \mathrm{~mm}$ and $10 \mathrm{~mm}$ grain size and even though the mantle viscosity dropped from a minimum of 
$10^{19}$ Pas to below $10^{18}$ Pas, the strain rate field at the surface remained identical. We also tested asymmetric boundary conditions, where we applied the full extension rate to one model side while keeping the opposite side fixed. Since there are no shear tractions allowed across the bottom, top, front, and back boundaries, the results are invariant with respect to asymmetric boundary conditions.

Localization dynamics of faults and shear zones depend on the included weakening mechanisms and the employed numerical resolution [Buiter et al., 2006, 2016]. Reducing the element size to $10 \mathrm{~km}$ and/or switching off strain softening for model A1 indeed changes the temporal evolution of the rift. However, after sufficient model time the resulting deformation patterns are qualitatively similar to the reference model (Fig. 6). We conducted models where we used rift velocities of $3 \mathrm{~mm} / \mathrm{yr}$ and $5 \mathrm{~mm} / \mathrm{yr}$ (full rate) covering the plausible range from plate reconstructions and geological indicators (cf Section 3). The deformation pattern after the same amount of extension featured some small differences, but qualitatively the structures remained the same. Finally, we varied the obliquity of the inherited Mesozoic rift between 0 and 60 degrees (measured between the domain trend and the extension normal), while all other parameters were identical to model A1. For higher obliquities, the effect that the rifts avoid cutting into the transversal domain is enhanced. For low obliquities, the effect is less pronounced and at no obliquity it disappears (Supplementary Figure S2).

\section{Discussion}

\subsection{Along-strike differences in deformation style}

The two independent modeling approaches, crustal-scale analog experiments and numerical lithospheric-scale models, were able to reproduce the significant along-axis differences in style and distribution of deformation between the Ethiopia/Kenya rift valleys and the Turkana depression. In particular, both modeling approaches showed a transition from localized deformation in the rift valley domains characterized by large marginal escarpments to a diffuse deformation within the Mesozoic rift, accommodated by a large number of minor faults with limited vertical displacement. Our results therefore highlight the important role of the transversal pre-existing heterogeneity with thinned crust and lithosphere in the Turkana region on the style and distribution of deformation during Cenozoic rifting.

Our findings confirm previous works [Ebinger et al., 2000] in that the width of deformation within the Turkana depression has no similarity to patterns in broad rift zones that developed in relatively hot lithosphere, such as the Basin and Range and Aegean extensional provinces [Buck, 1991; Brun, 1999; Labrousse et al., 2016]. Instead, the anomalously wide rift zone is caused by the N-S propagation of the Main Ethiopian and Kenya rift systems into a region of thinned crust, with mantle lithosphere that is stronger than that next to the inherited Mesozoic heterogeneity.

Highly oblique rifts are typically characterized by a wider deformation zone than more orthogonal rifts [e.g. Corti, 2012; Brune, 2014]; since the reactivation of the NW-SEtrending heterogeneity under roughly E-W extension results in a high obliquity of $60^{\circ}$, this may indicate a control exerted by rift obliquity on the anomalously wide deformation domain in the Turkana depression. However, highly oblique rifts feature complex fault patterns that are typically dominated by faults which are not orthogonal or sub-orthogonal to extension but are instead oblique or highly oblique to this direction [see for instance 
Agostini et al., 2009]. These patterns are very different from what is observed in the Turkana depression, where deformation is characterized by subparallel fault domains trending roughly N-S (i.e., roughly extension-orthogonal). This indicates that faults in the Turkana depression respond directly to the roughly E-W Nubia-Somalia motion and that the high rift obliquity does not play a major role in controlling the style and distribution of deformation. Moreover, the very good correspondence between our model results and the distribution and characteristics of deformation in the Turkana depression suggests a negligible influence exerted by the Western Branch on the interaction between the Kenyan and Ethiopian Rifts. This is also supported by the lack of significant volcanotectonic activity in a large region close to the border between South Sudan and Kenya, west of Lake Turkana.

The numerical models predict a progressive narrowing of deformation within the preexisting Mesozoic rift, which is in agreement with the eastward migration of deformation from basins in the western portion of the Turkana depression to more central domains (e.g., Lake Turkana itself and surrounding areas) [Ebinger et al., 2000 and references therein]. However, the sedimentary basins West of Lake Turkana, which started developing prior to $25 \mathrm{Ma}$, likely predate Nubia-Somalia divergence [laffaldano et al., 2014; DeMets and Merkouriev, 2016] and therefore were not strictly related to the Tertiary rifting event sensu stricto. Consequently, other processes, such as deep-seated asthenospheric processes (plume impingement at the base of the lithosphere) [Ebinger et al., 2000] or strain hardening between episodes of extension [Morley et al., 1992] likely contributed to the observed evolution.

\subsection{Characteristics of rift linkage within the Turkana depression}

Both our analog model and Types 1-3 of the numerical models depict the tendency of the rift valleys to propagate preferentially to SE (Ethiopia) or to the NW (Kenya) instead of linking up directly. As explained in Section 2, this reproduces a key natural observation. In fact, extensional deformation related to the Kenya rift is shifted to the NW to form the narrow depression hosting Lake Turkana; similarly, the Ethiopian rift is progressively shifted to the SE forming the Ririba rift and Hurri hills [Ebinger et al., 2000; Bonini et al., 2005].

What is the tectonic reason for diverting the Ethiopian and Kenya rifts towards the east and west, respectively? Our models show that this pattern occurs during the very beginning of deformation (Fig. 6a), so it can not be related to evolving variables such as strain softening or crustal thinning, as evoked for 2D rift migration [Kusznir and Park, 1987; van Wijk and Cloetingh, 2002; Brune et al., 2014; Svartman Dias et al., 2015; Jammes and Lavier, 2016]. We find that strength variations in crust and mantle play a first-order role in controlling the regional rift architecture. However, mode selection is not controlled by the vertically integrated lithosphere strength. If this was the case, models where the central domain is weaker than the plateaus outside of the rift zones, such as the analog model and numerical models A1, B3, B17, B18, B21, B22, B25, B26, would not feature the left-lateral bend at the segment boundary. Therefore we suggest that there is a hierarchy of dominating processes: (1) On crustal level, localization is solely controlled by brittle localization dynamics and stress focusing due to rift propagation into the transversal pre-existing heterogeneity. This agrees with previous modeling [Acocella et al., 1999] that in conditions of orthogonal rifting (i.e., the extension direction is perpendicular to the rift trend) when the angle between the rift margins and the margins of the pre-existing heterogeneity is $>90^{\circ}$ reactivation of its boundaries is favored; 
conversely, when the angle is $<90^{\circ}$ reactivation is less probable (Fig. 9). (2) However, if we account for the existence of lithospheric and asthenospheric mantle, these crustal processes are largely overruled by lithospheric thinning. In this case, it is the mantle strength that has first-order control on the transition from left-bending type to straight linkage and right-bending type while second-order deviations of this rule are due to crustal processes. When applying our results to nature, we suggest that both processes facilitate localization of deformation at the NW termination of the Kenya rift as well as at the SE tip of the Ethiopian Rift (Fig. 9), promoting the propagation of this latter to the SE and that of the Kenyan domain towards the NW.

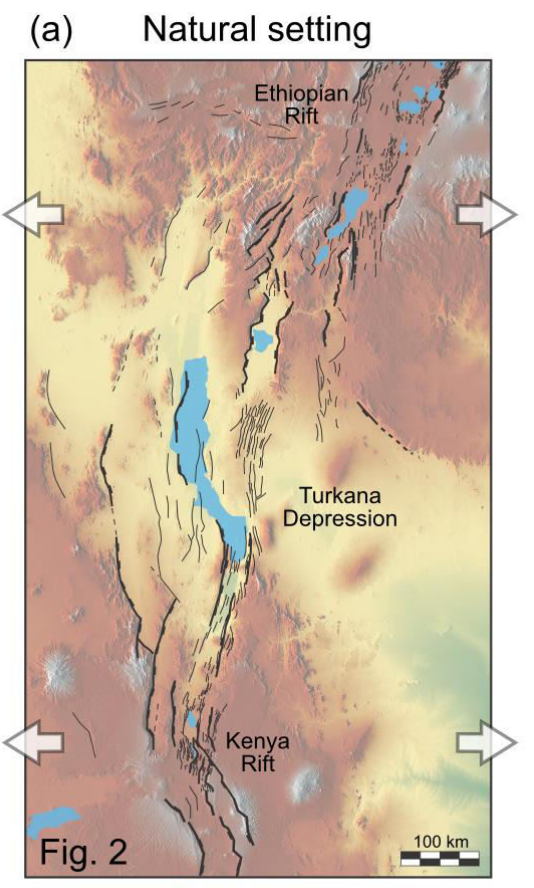

(c) Numerical model

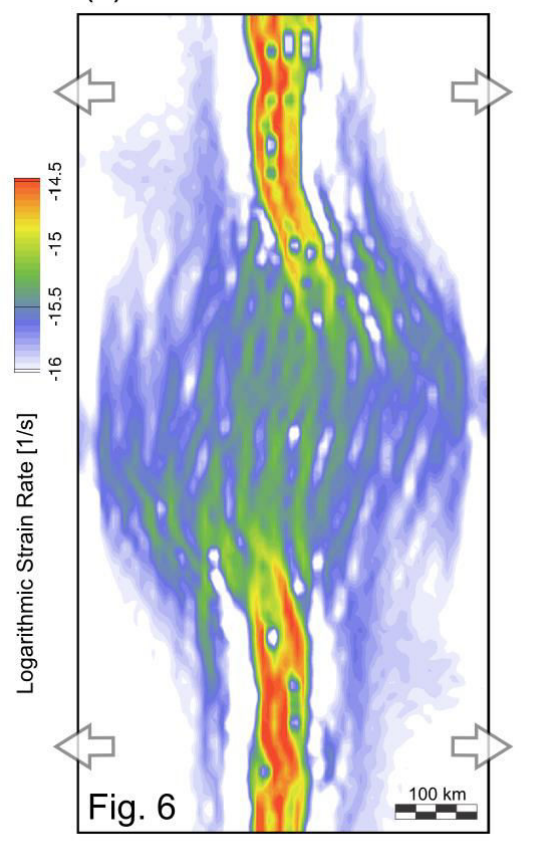

(b) Analog model

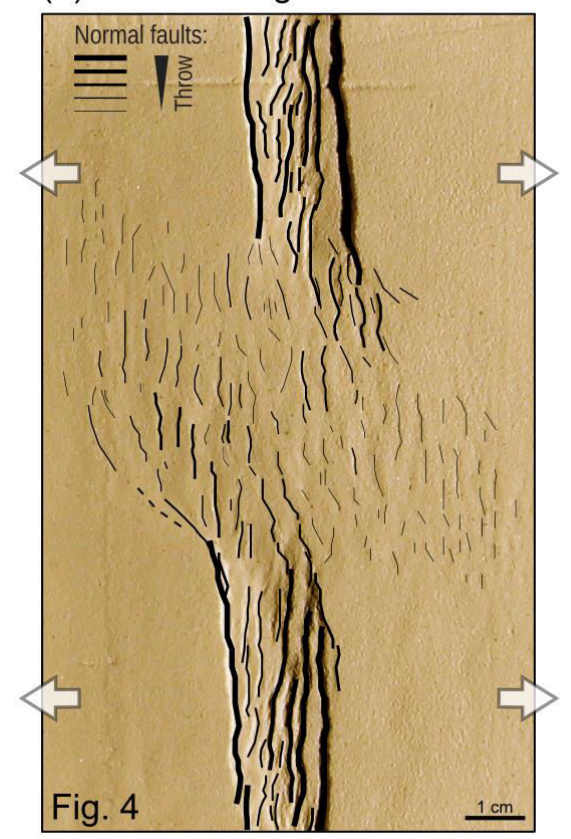

(d) Conceptual result

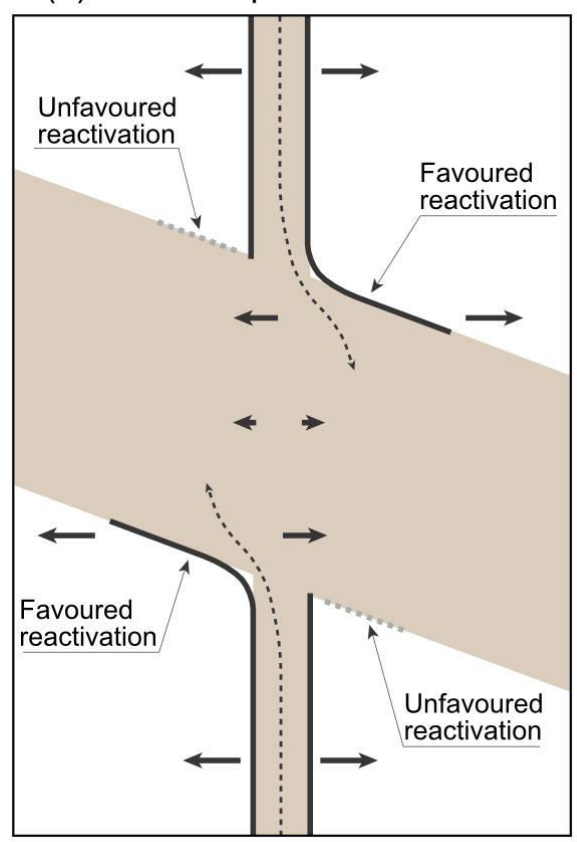

Fig. 9. Summary plot. (a) Major faults of the study area. (b) Key features of the analog model. (c) Final deformation pattern of numerical reference model A1. (d) Summarizing interpretation (see text for details). 


\subsection{Influence of the pre-existing lithospheric structure on the local fault pattern}

Besides capturing the large-scale picture of rift interaction, our analog modeling indicates that the pre-existing variations in strength of the different domains have an important control on the fault pattern at a more local scale. For instance, the models indicate significant reactivation of the boundaries between the Turkana domain and the strong surrounding plateaus, giving rise to NW-SE faults at the margins of the preexisting transversal heterogeneity, which are a continuation of the boundary faults of the main rift valleys. A similar feature can be hypothesized in nature at both the southern tip of the Ethiopian Rift (where NW-SE faults characterize the margins of the pre-existing Anza graben, East of the Ririba Rift) and the NW termination of the Kenya rift (where NW-SE to NNW-SSE-trending faults give rise to the large Turkwell escarpment; Figs. 2 and 9). In this latter case, the NW-SE faults typically curve at their tip to acquire a more $\mathrm{N}-\mathrm{S}$ to NNE-SSW trend, a characteristic that is observed in the analog models. This feature resembles the horse-tail splays at the termination of transcurrent faults and likely result from the component of strike-slip motion at the margins of the Turkana depression imposed by the relative orientation between boundary of the pre-existing transversal heterogeneity and the extension direction (Fig. 9).

Another interesting feature within the fault pattern is the presence of numerous NWSE-trending minor faults or fault segments, which develop with a high obliquity to the extension direction but sub-parallel to the transversal pre-existing domain (Fig. 4b). In places, these segments tend to connect $\mathrm{N}$-S structures, resulting in highly segmented NNW-SSE-trending normal faults with a typical zig-zag plan-view geometry. In turn, these fault systems bound highly segmented basins, which result from the coalescence of enechelon N-S trending sub-basins connected by NW-SE segments. This geometry strikingly resembles the typical 'staircase' pattern of the basin hosting Lake Turkana. Although this architecture has been suggested to be controlled by the reactivation of preexisting, discrete upper crustal fabrics [Vetel and Le Gall, 2006], our laterally homogenous models indicate that this architecture may result from the complex stress field developing within the area of wide deformation, which is controlled by rift propagation, the geometry of the pre-existing domains and the direction of extension (Fig. 9). We cannot however exclude that on a local scale pre-existing discrete heterogeneities may have controlled fault development and architecture [Vetel and Le Gall, 2006].

\section{Conclusions}

In order to elucidate the interaction between the Ethiopian and Kenyan rift valleys within the Turkana depression, we have integrated crustal-scale, isothermal analog experiments with lithospheric-scale, thermo-mechanical numerical models. This integration and the comparison of the results with nature leads us to draw the following conclusions:

(1) The along-axis transition from narrow rift valleys in Ethiopia/Kenya to a distributed deformation within the Turkana depression results from inherited lithospheric strength variations. In particular, the anomalously wide rift zone is controlled by the presence of a NW-SE region of thinned crust resulting from Mesozoic rifting.

(2) Within the Turkana region, the Kenyan and Ethiopian rift valleys are deflected leftlaterally away from one another, avoiding a direct link to form a throughgoing N-S depression. We find that this is primarily linked to the mantle lithospheric strength of the 
transversal pre-existing heterogeneity, but also influenced by stress focusing effects and upper crustal fault dynamics.

(3) Local-scale characteristics of the fault pattern, such as the occurrence of horse-tail splays at fault terminations or the presence of faults with zig-zag plan-view geometry giving rise to basins with a 'staircase' pattern as in the case of Lake Turkana, may result from a minor component of strike-slip motion controlled by relative orientation between the geometry of the pre-existing domains and the direction of extension.

\section{References}

Acocella, V., C. Faccenna, R. Funiciello, and F. Rossetti (1999), Sand-box modelling of basement-controlled transfer zones in extensional domains, Terra Nova, 11(4), 149-156, doi:10.1046/j.1365-3121.1999.00238.x.

Agostini, A., G. Corti, A. Zeoli, and G. Mulugeta (2009), Evolution, pattern, and partitioning of deformation during oblique continental rifting: Inferences from lithospheric-scale centrifuge models, Geochem. Geophys. Geosystems, 10, Q11015, doi:10.1029/2009GC002676.

Balestrieri, M. L., M. Bonini, G. Corti, F. Sani, and M. Philippon (2016), A refinement of the chronology of rift-related faulting in the Broadly Rifted Zone, southern Ethiopia, through apatite fission-track analysis, Tectonophysics, 671, 42-55, doi:10.1016/j.tecto.2016.01.012.

Benoit, M. H., A. A. Nyblade, and M. E. Pasyanos (2006), Crustal thinning between the Ethiopian and East African plateaus from modeling Rayleigh wave dispersion, Geophys. Res. Lett., 33(13), L13301, doi:10.1029/2006GL025687.

Bonini, M., G. Corti, F. Innocenti, P. Manetti, F. Mazzarini, T. Abebe, and Z. Pecskay (2005), Evolution of the Main Ethiopian Rift in the frame of Afar and Kenya rifts propagation, Tectonics, 24(1), TC1007, doi:10.1029/2004TC001680.

Bos, B., and C. J. Spiers (2002), Frictional-viscous flow of phyllosilicate-bearing fault rock: Microphysical model and implications for crustal strength profiles, J. Geophys. Res. Solid Earth, 107(2), 1-1-1-13.

Brun, J.-P. (1999), Narrow rifts versus wide rifts: inferences for the mechanics of rifting from laboratory experiments, Philos. Trans. R. Soc. Lond. Ser. Math. Phys. Eng. Sci., 357(1753), 695-712, doi:10.1098/rsta.1999.0349.

Brune, S. (2014), Evolution of stress and fault patterns in oblique rift systems: 3-D numerical lithospheric-scale experiments from rift to breakup, Geochem. Geophys. Geosystems, 15(8), 3392-3415, doi:10.1002/2014GC005446.

Brune, S. (2016), Rifts and rifted margins: A review of geodynamic processes and natural hazards, edited by J. C. Duarte and W. P. Schellart, Plate Boundaries Nat. Hazards, 1137, doi:10.1002/9781119054146.ch2.

Brune, S., and J. Autin (2013), The rift to break-up evolution of the Gulf of Aden: Insights from 3D numerical lithospheric-scale modelling, Tectonophysics, 607, 65-79, doi:10.1016/j.tecto.2013.06.029.

Brune, S., A. A. Popov, and S. V. Sobolev (2012), Modeling suggests that oblique extension facilitates rifting and continental break-up, J. Geophys. Res., 117(B8), B08402, doi:10.1029/2011JB008860.

Brune, S., A. A. Popov, and S. V. Sobolev (2013), Quantifying the thermo-mechanical impact of plume arrival on continental break-up, Tectonophysics, 604, 51-59, doi:10.1016/j.tecto.2013.02.009.

Brune, S., C. Heine, M. Perez-Gussinye, and S. V. Sobolev (2014), Rift migration explains continental margin asymmetry and crustal hyper-extension, Nat. Commun., 5(4014), doi:10.1038/ncomms5014.

Brune, S., S. E. Williams, N. P. Butterworth, and R. D. Müller (2016), Abrupt plate accelerations shape rifted continental margins, Nature, 536(7615), 201-204, doi:10.1038/nature18319. 
Brune, S., C. Heine, P. D. Clift, and M. Pérez-Gussinyé (2017), Rifted margin architecture and crustal rheology: Reviewing Iberia-Newfoundland, Central South Atlantic, and South China Sea, Mar. Pet. Geol., 79, 257-281, doi:10.1016/j.marpetgeo.2016.10.018.

Buck, W. R. (1991), Modes of Continental Lithospheric Extension, J. Geophys. Res.-Solid Earth, 96(B12), 20161-20178, doi:10.1029/91JB01485.

Buiter, S. J. H., A. Y. Babeyko, S. Ellis, T. V. Gerya, B. J. P. Kaus, A. Kellner, G. Schreurs, and Y. Yamada (2006), The numerical sandbox: comparison of model results for a shortening and an extension experiment, Geol. Soc. Lond. Spec. Publ., 253(1), 29-64, doi:10.1144/GSL.SP.2006.253.01.02.

Buiter, S. J. H. et al. (2016), Benchmarking numerical models of brittle thrust wedges, J. Struct. Geol., 92, 140-177, doi:10.1016/j.jsg.2016.03.003.

Bürgmann, R., and G. Dresen (2008), Rheology of the Lower Crust and Upper Mantle: Evidence from Rock Mechanics, Geodesy, and Field Observations, Annu. Rev. Earth Planet. Sci., 36(1), 531-567.

Chorowicz, J. (2005), The East African rift system, J. Afr. Earth Sci. , 43(1-3), 379-410, doi:10.1016/j.jafrearsci.2005.07.019.

Christensen, N. I., and W. D. Mooney (1995), Seismic velocity structure and composition of the continental crust: A global view, J. Geophys. Res. Solid Earth, 100(B6), 9761-9788, doi:10.1029/95JB00259.

Clift, P. D., S. Brune, and J. Quinteros (2015), Climate changes control offshore crustal structure at South China Sea continental margin, Earth Planet. Sci. Lett., 420, 66-72, doi:10.1016/j.epsl.2015.03.032.

Corti, G. (2009), Continental rift evolution: From rift initiation to incipient break-up in the Main Ethiopian Rift, East Africa, Earth-Sci. Rev., 96(1-2), 1-53, doi:doi: DOI: 10.1016/j.earscirev.2009.06.005.

Corti, G. (2012), Evolution and characteristics of continental rifting: Analog modeling-inspired view and comparison with examples from the East African Rift System, Tectonophysics, 522523, 1-33, doi:10.1016/j.tecto.2011.06.010.

Corti, G., M. Bonini, S. Conticelli, F. Innocenti, P. Manetti, and D. Sokoutis (2003), Analog modelling of continental extension: a review focused on the relations between the patterns of deformation and the presence of magma, Earth-Sci. Rev., 63(3-4), 169-247, doi:10.1016/S0012-8252(03)00035-7.

Cyprych, D., S. Brune, S. Piazolo, and J. Quinteros (2016), Strain localization in polycrystalline material with second phase particles: Numerical modeling with application to ice mixtures, Geochem. Geophys. Geosystems, doi:10.1002/2016GC006471.

Davidson, A., and D. C. Rex (1980), Age of volcanism and rifting in southwestern Ethiopia, Nature, 283(5748), 657-658, doi:10.1038/283657a0.

DeMets, C., and S. Merkouriev (2016), High-resolution estimates of Nubia-Somalia plate motion since $20 \mathrm{Ma}$ from reconstructions of the Southwest Indian Ridge, Red Sea and Gulf of Aden, Geophys. J. Int., 207(1), 317-332, doi:10.1093/gji/ggw276.

Duesterhoeft, E., J. Quinteros, R. Oberhänsli, R. Bousquet, and C. de Capitani (2014), Relative impact of mantle densification and eclogitization of slabs on subduction dynamics: A numerical thermodynamic/thermokinematic investigation of metamorphic density evolution, Tectonophysics, doi:10.1016/j.tecto.2014.09.009.

Dunbar, J. A., and D. S. Sawyer (1988), Continental rifting at pre-existing lithospheric weaknesses, Nature, 333(6172), 450-452, doi:10.1038/333450a0.

Ebinger, C., Y. P. Djomani, E. Mbede, A. Foster, and J. B. Dawson (1997), Rifting Archaean lithosphere: the Eyasi-Manyara-Natron rifts, East Africa, J. Geol. Soc., 154(6), 947-960, doi:10.1144/gsjgs.154.6.0947.

Ebinger, C. J., and N. H. Sleep (1998), Cenozoic magmatism throughout east Africa resulting from impact of a single plume, Nature, 395(6704), 788-791, doi:10.1038/27417. 
Ebinger, C. J., J. A. Jackson, A. N. Foster, and N. J. Hayward (1999), Extensional basin geometry and the elastic lithosphere, Philos. Trans. R. Soc. Lond. Ser. Math. Phys. Eng. Sci., 357(1753), 741-765, doi:10.1098/rsta.1999.0351.

Ebinger, C. J., T. Yemane, D. J. Harding, S. Tesfaye, S. Kelley, and D. C. Rex (2000), Rift deflection, migration, and propagation: Linkage of the Ethiopian and Eastern rifts, Africa, GSA Bull., 112(2), 163-176, doi:10.1130/00167606(2000)112\&lt;163:RDMAPL\&gt;2.0.CO;2.

Emishaw, L., D. A. Laó-Dávila, M. G. Abdelsalam, E. A. Atekwana, and S. S. Gao (2017), Evolution of the broadly rifted zone in southern Ethiopia through gravitational collapse and extension of dynamic topography, Tectonophysics, 699, 213-226, doi:10.1016/j.tecto.2016.12.009.

Faulds, J. E., and R. J. Varga (1998), The role of accommodation zones and transfer zones in the regional segmentation of extended terranes, Geol. Soc. Am. Spec. Pap., 323, 1-45, doi:10.1130/0-8137-2323-X.1.

Fishwick, S. (2010), Surface wave tomography: Imaging of the lithosphere-asthenosphere boundary beneath central and southern Africa?, Lithos, 120(1-2), 63-73, doi:10.1016/j.lithos.2010.05.011.

Fishwick, S., and I. D. Bastow (2011), Towards a better understanding of African topography: a review of passive-source seismic studies of the African crust and upper mantle, Geol. Soc. Lond. Spec. Publ., 357(1), 343-371, doi:10.1144/SP357.19.

Flament, N., M. Gurnis, and R. D. Müller (2013), A review of observations and models of dynamic topography, Lithosphere, 5(2), 189-210, doi:10.1130/L245.1.

George, R., N. Rogers, and S. Kelley (1998), Earliest magmatism in Ethiopia: Evidence for two mantle plumes in one flood basalt province, Geology, 26(10), 923-926, doi:10.1130/00917613(1998)026<0923:EMIEEF>2.3.CO;2.

Gleason, G. C., and J. Tullis (1995), A Flow Law for Dislocation Creep of Quartz Aggregates Determined with the Molten-Salt Cell, Tectonophysics, 247(1-4), 1-23.

Hansen, S. E., and A. A. Nyblade (2013), The deep seismic structure of the Ethiopia/Afar hotspot and the African superplume, Geophys. J. Int., 194(1), 118-124, doi:10.1093/gji/ggt116.

Hautot, S., P. Tarits, K. Whaler, B. Le Gall, J.-J. Tiercelin, and C. Le Turdu (2000), Deep structure of the Baringo Rift Basin (central Kenya) from three-dimensional magnetotelluric imaging: Implications for rift evolution, J. Geophys. Res. Solid Earth, 105(B10), 23493-23518, doi:10.1029/2000JB900213.

Heine, C., and S. Brune (2014), Oblique rifting of the Equatorial Atlantic: Why there is no Saharan Atlantic Ocean, Geology, 42(3), 211-214, doi:10.1130/G35082.1.

Hendrie, D. B., N. J. Kusznir, C. K. Morley, and C. J. Ebinger (1994), Cenozoic extension in northern Kenya: a quantitative model of rift basin development in the Turkana region, Tectonophysics, 236(1), 409-438, doi:10.1016/0040-1951(94)90187-2.

Hirth, G., and D. L. Kohlstedt (2003), Rheology of the upper mantle and the mantle wedge: A view from the experimentalists, Geophys. Monogr., 138, 83-105.

Hoggard, M. J., N. White, and D. Al-Attar (2016), Global dynamic topography observations reveal limited influence of large-scale mantle flow, Nat. Geosci., 9(6), 456-463, doi:10.1038/ngeo2709.

Huismans, R. S., and C. Beaumont (2011), Depth-dependent extension, two-stage breakup and cratonic underplating at rifted margins, Nature, 473(7345), 74-78, doi:10.1038/nature09988.

laffaldano, G., R. Hawkins, and M. Sambridge (2014), Bayesian noise-reduction in Arabia/Somalia and Nubia/Arabia finite rotations since $\sim 20 \mathrm{Ma}$ : Implications for Nubia/Somalia relative motion, Geochem. Geophys. Geosystems, 15(4), 845-854, doi:10.1002/2013GC005089.

Jammes, S., and L. L. Lavier (2016), The effect of bimineralic composition on extensional processes at lithospheric scale, Geochem. Geophys. Geosystems, 17(8), 3375-3392, doi:10.1002/2016GC006399. 
Karato, S.-I., and H. Jung (2003), Effects of pressure on high-temperature dislocation creep in olivine, Philos. Mag., 83(3), 401-414, doi:10.1080/0141861021000025829.

Katz, R. F., R. Ragnarsson, and E. Bodenschatz (2005), Tectonic microplates in a wax model of sea-floor spreading, New J. Phys., 7, 37-37, doi:10.1088/1367-2630/7/1/037.

Keller, G. R. et al. (1994), Crustal and upper mantle structure of the Kenya Rift The East African rift system in the light of KRISP 90, Tectonophysics, 236(1), 465-483, doi:10.1016/00401951(94)90190-2.

Keranen, K. M., S. L. Klemperer, J. Julia, J. F. Lawrence, and A. A. Nyblade (2009), Low lower crustal velocity across Ethiopia: Is the Main Ethiopian Rift a narrow rift in a hot craton?, Geochem. Geophys. Geosystems, 10(5), Q0AB01, doi:10.1029/2008GC002293.

Koehn, D., K. Aanyu, S. Haines, and T. Sachau (2008), Rift nucleation, rift propagation and the creation of basement micro-plates within active rifts, Tectonophysics, 458(1-4), 105-116, doi:10.1016/j.tecto.2007.10.003.

Koopmann, H., S. Brune, D. Franke, and S. Breuer (2014), Linking rift propagation barriers to excess magmatism at volcanic rifted margins, Geology, G36085.1, doi:10.1130/G36085.1.

Kusznir, N. J., and R. G. Park (1987), The extensional strength of the continental lithosphere: its dependence on geothermal gradient, and crustal composition and thickness, Geol. Soc. Lond. Spec. Publ., 28(1), 35-52.

Labrousse, L., B. Huet, L. Le Pourhiet, L. Jolivet, and E. Burov (2016), Rheological implications of extensional detachments: Mediterranean and numerical insights, Earth-Sci. Rev., 161, 233-258, doi:10.1016/j.earscirev.2016.09.003.

Le Pourhiet, L., D. A. May, L. Huille, L. Watremez, and S. Leroy (2017), A genetic link between transform and hyper-extended margins, Earth Planet. Sci. Lett., 465, 184-192, doi:10.1016/j.epsl.2017.02.043.

Maguire, P. K. H. et al. (2006), Crustal structure of the northern Main Ethiopian Rift from the EAGLE controlled-source survey; a snapshot of incipient lithospheric break-up, Geol. Soc. Lond. Spec. Publ., 259(1), 269-292, doi:10.1144/GSL.SP.2006.259.01.21.

Melnick, D., Y. Garcin, J. Quinteros, M. R. Strecker, D. Olago, and J.-J. Tiercelin (2012), Steady rifting in northern Kenya inferred from deformed Holocene lake shorelines of the Suguta and Turkana basins, Earth Planet. Sci. Lett., 331-332, 335-346, doi:10.1016/j.epsl.2012.03.007.

Mohr, P. (1983), Volcanotectonic aspects of the Ethiopian Rift evolution, Bull Cent Rech Explor Prod Elf-Aquitaine, 7, 175-189.

Molnar, N. E., A. R. Cruden, and P. G. Betts (2017), Interactions between propagating rotational rifts and linear rheological heterogeneities: insights from three-dimensional laboratory experiments, Tectonics, 2016TC004447, doi:10.1002/2016TC004447.

Moore, J. M., and A. Davidson (1978), Rift structure in southern Ethiopia, Tectonophysics, 46, 159-173, doi:10.1016/0040-1951(78)90111-7.

Morley, C. K. (1999), Influence of Preexisting Fabrics on Rift Structure, , 151-160.

Morley, C. K. (2002), Evolution of Large Normal Faults: Evidence from Seismic Reflection Data, AAPG Bull., 86(6), 961-978, doi:10.1306/61EEDBFC-173E-11D7-8645000102C1865D.

Morley, C. K., R. A. Nelson, T. L. Patton, and S. G. Munn (1990), Transfer Zones in the East African Rift System and Their Relevance to Hydrocarbon Exploration in Rifts (1), AAPG Bull., 74(8), 1234-1253.

Morley, C. K., W. A. Wescott, D. M. Stone, R. M. Harper, S. T. Wigger, and F. M. Karanja (1992), Tectonic evolution of the northern Kenyan Rift, J. Geol. Soc., 149(3), 333-348, doi:10.1144/gsjgs.149.3.0333.

Naliboff, J., and S. J. H. Buiter (2015), Rift reactivation and migration during multiphase extension, Earth Planet. Sci. Lett., 421, 58-67, doi:10.1016/j.epsl.2015.03.050.

Pasyanos, M. E., T. G. Masters, G. Laske, and Z. Ma (2014), LITHO1.0: An updated crust and lithospheric model of the Earth, J. Geophys. Res. Solid Earth, 119(3), 2013JB010626, doi:10.1002/2013JB010626. 
Philippon, M., G. Corti, F. Sani, M. Bonini, M.-L. Balestrieri, P. Molin, E. Willingshofer, D. Sokoutis, and S. Cloetingh (2014), Evolution, distribution and characteristics of rifting in southern Ethiopia, Tectonics, n/a-n/a, doi:10.1002/2013TC003430.

Pik, R., B. Marty, J. Carignan, G. Yirgu, and T. Ayalew (2008), Timing of East African Rift development in southern Ethiopia: Implication for mantle plume activity and evolution of topography, Geology, 36(2), 167-170, doi:10.1130/G24233A.1.

Popov, A. A., and S. V. Sobolev (2008), SLIM3D: A tool for three-dimensional thermo mechanical modeling of lithospheric deformation with elasto-visco-plastic rheology, Phys. Earth Planet. Inter., 171(1-4), 55-75, doi:10.1016/j.pepi.2008.03.007.

Popov, A. A., S. V. Sobolev, and M. D. Zoback (2012), Modeling evolution of the San Andreas Fault system in northern and central California, Geochem. Geophys. Geosystems, 13(8), Q08016, doi:10.1029/2012GC004086.

Quinteros, J., and S. V. Sobolev (2012), Why has the Nazca plate slowed since the Neogene?, Geology, 41(1), 31-34, doi:10.1130/G33497.1.

Quinteros, J., S. V. Sobolev, and A. A. Popov (2010), Viscosity in transition zone and lower mantle: Implications for slab penetration, Geophys. Res. Lett., 37, L09307.

Ramberg, H. (1981), Gravity, deformation, and the earth's crust: In theory, experiments, and geological application, Academic press.

Rosendahl, B. R. (1987), Architecture of Continental Rifts with Special Reference to East Africa, Annu. Rev. Earth Planet. Sci., 15(1), 445-503, doi:10.1146/annurev.ea.15.050187.002305.

Rubey, M., S. Brune, C. Heine, D. R. Davies, S. E. Williams, and R. D. Müller (2017), Global patterns of Earth's dynamic topography since the Jurassic, Solid Earth Discuss., 1-34, doi:10.5194/se-2017-26.

Rutter, E. H., and K. H. Brodie (2004), Experimental grain size-sensitive flow of hot-pressed Brazilian quartz aggregates, J. Struct. Geol., 26(11), 2011-2023, doi:10.1016/j.jsg.2004.04.006.

Rybacki, E., and G. Dresen (2000), Dislocation and diffusion creep of synthetic anorthite aggregates, J. Geophys. Res., 105(B11), 26,017-26,036, doi:10.1029/2000JB900223.

Rybacki, E., M. Gottschalk, R. Wirth, and G. Dresen (2006), Influence of water fugacity and activation volume on the flow properties of fine-grained anorthite aggregates, J. Geophys. Res. Solid Earth, 111(B3), B03203, doi:10.1029/2005JB003663.

Saria, E., E. Calais, D. S. Stamps, D. Delvaux, and C. J. H. Hartnady (2014), Present-day kinematics of the East African Rift, J. Geophys. Res. Solid Earth, 119(4), 3584-3600, doi:10.1002/2013JB010901.

Sembroni, A., C. Faccenna, T. W. Becker, P. Molin, and B. Abebe (2016), Long-term, deepmantle support of the Ethiopia-Yemen Plateau, Tectonics, 35, 469-488, doi:10.1002/2015TC004000.

Sippel, J., C. Meeßen, M. Cacace, J. Mechie, S. Fishwick, C. Heine, M. Scheck-Wenderoth, and M. R. Strecker (2017), The Kenya rift revisited: insights into lithospheric strength through data-driven 3-D gravity and thermal modelling, Solid Earth, 8(1), 45-81, doi:10.5194/se-845-2017.

Stamps, D. S., L. M. Flesch, E. Calais, and A. Ghosh (2014), Current kinematics and dynamics of Africa and the East African Rift System, J. Geophys. Res. Solid Earth, 119(6), 5161-5186, doi:10.1002/2013JB010717.

Svartman Dias, A. E., L. L. Lavier, and N. W. Hayman (2015), Conjugate rifted margins width and asymmetry: The interplay between lithospheric strength and thermomechanical processes, J. Geophys. Res. Solid Earth, 120(12), 2015JB012074, doi:10.1002/2015JB012074.

Thybo, H., P. K. H. Maguire, C. Birt, and E. Perchuć (2000), Seismic reflectivity and magmatic underplating beneath the Kenya Rift, Geophys. Res. Lett., 27(17), 2745-2748, doi:10.1029/1999GL011294. 
Versfelt, J., and B. R. Rosendahl (1989), Relationships between pre-rift structure and rift architecture in Lakes Tanganyika and Malawi, East Africa, Nature, 337(6205), 354-357, doi:10.1038/337354a0.

Vetel, W., and B. Le Gall (2006), Dynamics of prolonged continental extension in magmatic rifts: the Turkana Rift case study (North Kenya), Geol. Soc. Lond. Spec. Publ., 259(1), 209233, doi:10.1144/GSL.SP.2006.259.01.17.

Vetel, W., B. Le Gall, and J. J. Walsh (2005), Geometry and growth of an inner rift fault pattern: the Kino Sogo Fault Belt, Turkana Rift (North Kenya), J. Struct. Geol., 27(12), 2204-2222, doi:10.1016/j.jsg.2005.07.003.

van Wijk, J., J. van Hunen, and S. Goes (2008), Small-scale convection during continental rifting: Evidence from the Rio Grande rift, Geology, 36(7), 575-578, doi:10.1130/G24691A.1.

van Wijk, J. W., and S. A. P. L. Cloetingh (2002), Basin migration caused by slow lithospheric extension, Earth Planet. Sci. Lett., 198(3-4), 275-288, doi:10.1016/S0012821X(02)00560-5.

Woldetinsae, G., and H.-J. Götze (2005), Gravity field and isostatic state of Ethiopia and adjacent areas, J. Afr. Earth Sci., 41(1-2), 103-117, doi:10.1016/j.jafrearsci.2005.02.004.

Ziegler, P. A., and S. Cloetingh (2004), Dynamic processes controlling evolution of rifted basins, Earth-Sci. Rev., 64(1-2), 1-50, doi:10.1016/S0012-8252(03)00041-2.

\section{Acknowledgements}

We thank two anonymous Reviewers and the Associate Editor for their useful suggestions, which helped to improve the paper. S. Brune was funded through the Helmholtz Young Investigators Group CRYSTALS (VH-NG-1132).

\section{Supplementary Materials}

Supplementary Animations display the evolution of selected models and are linked here:

[A1] Reference model for Rift Linkage Type 1 [Left-bending, Wide].

[A2] Alternative model for Rift Linkage Type 1 [Left-bending, Wide].

[A3] Characteristic model Rift Linkage Type 2 [Left-bending, Narrow].

[A4] Characteristic model Rift Linkage Type 3 [Left-bending, Microplate].

[A5] Characteristic model Rift Linkage Type 4 [Right-bending].

[A6] Characteristic model Rift Linkage Type 5 [Straight Linkage]. 
a

Extension $8 \mathrm{~mm}(64 \mathrm{~km})$

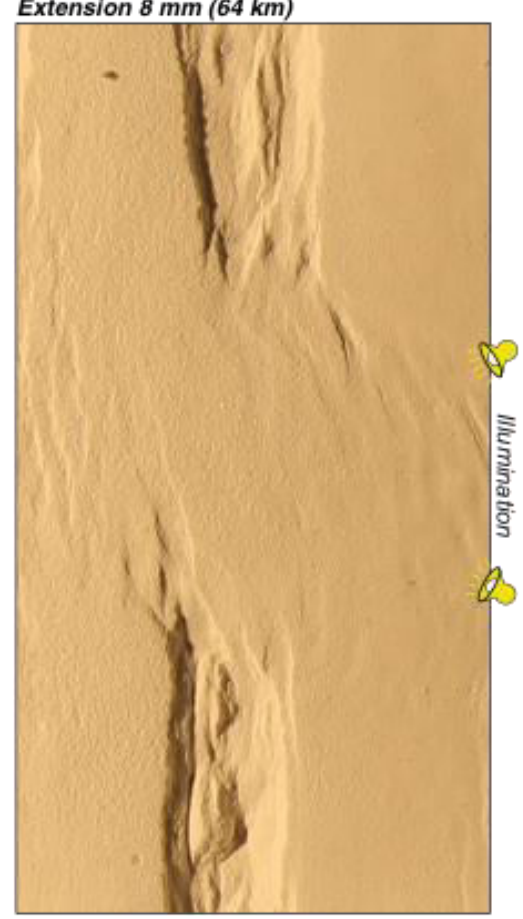

b

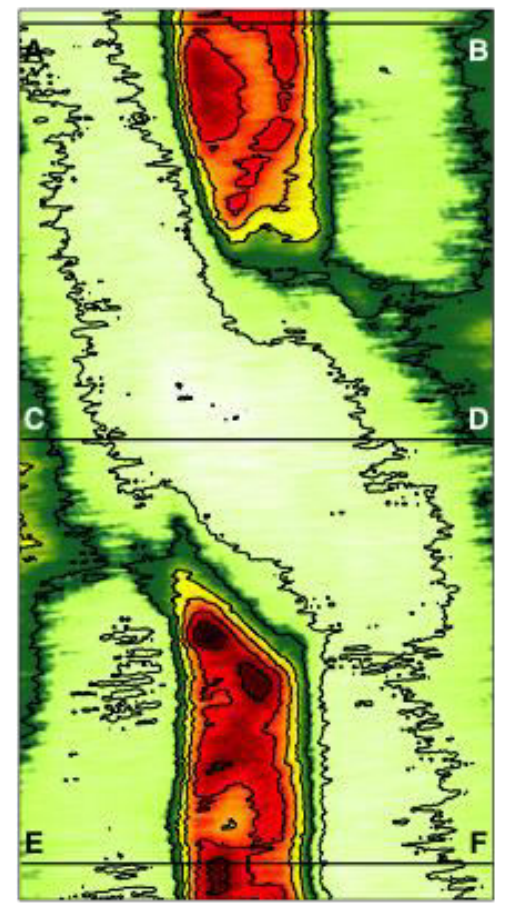

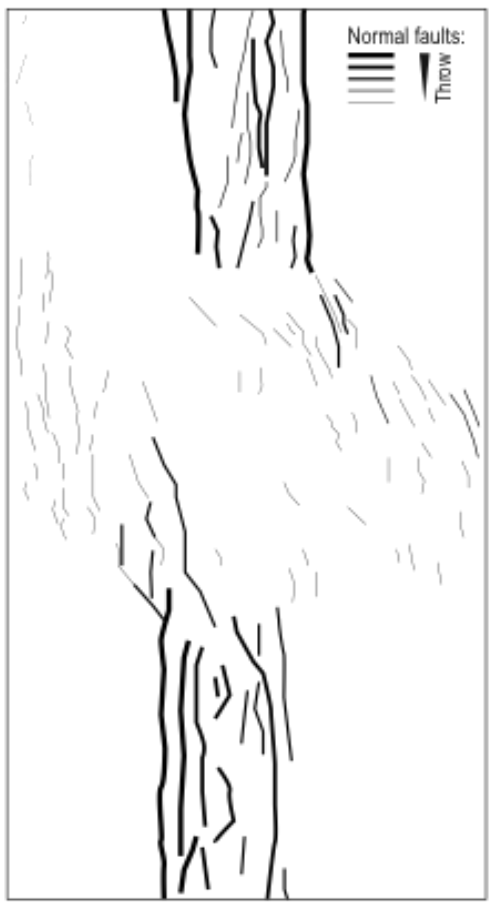
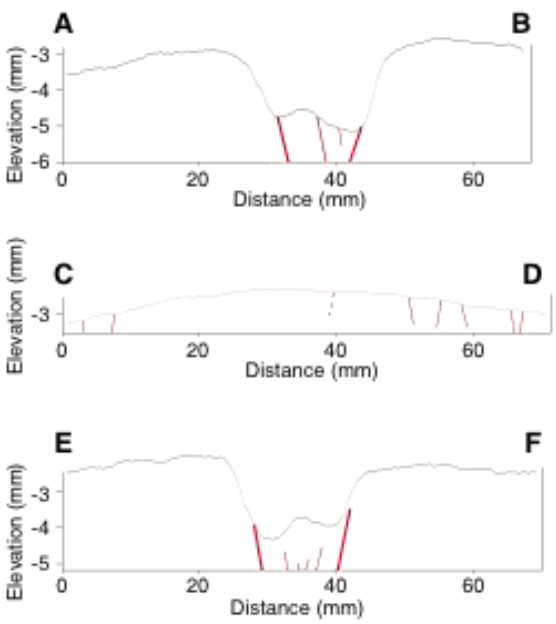

Supplementary Fig. S1. Alternative analog model. The set-up for the experiment is the same as the reference model, the only difference being the strength of the transversal Cretaceous Rift, which is slightly stronger than the Ethiopia and Kenya Rifts. This is due to a small increase of the upper crustal thickness with respect to the reference model. (a) Top-view photo of the analog model for $8 \mathrm{~mm}$ bulk extension (left panel) and line drawing of structures (right panel). (b) Digital elevation model of the surface (left panel) and topographic profiles (right panel) at the end of deformation $(8 \mathrm{~mm}$ bulk extension). A difference to the reference model is that the stronger rheology of the inherited transversal heterogeneity results in a less prominent deformation of the Turkana domain, with faulting more focused on external portions. This is in agreement with numerical modeling results. 

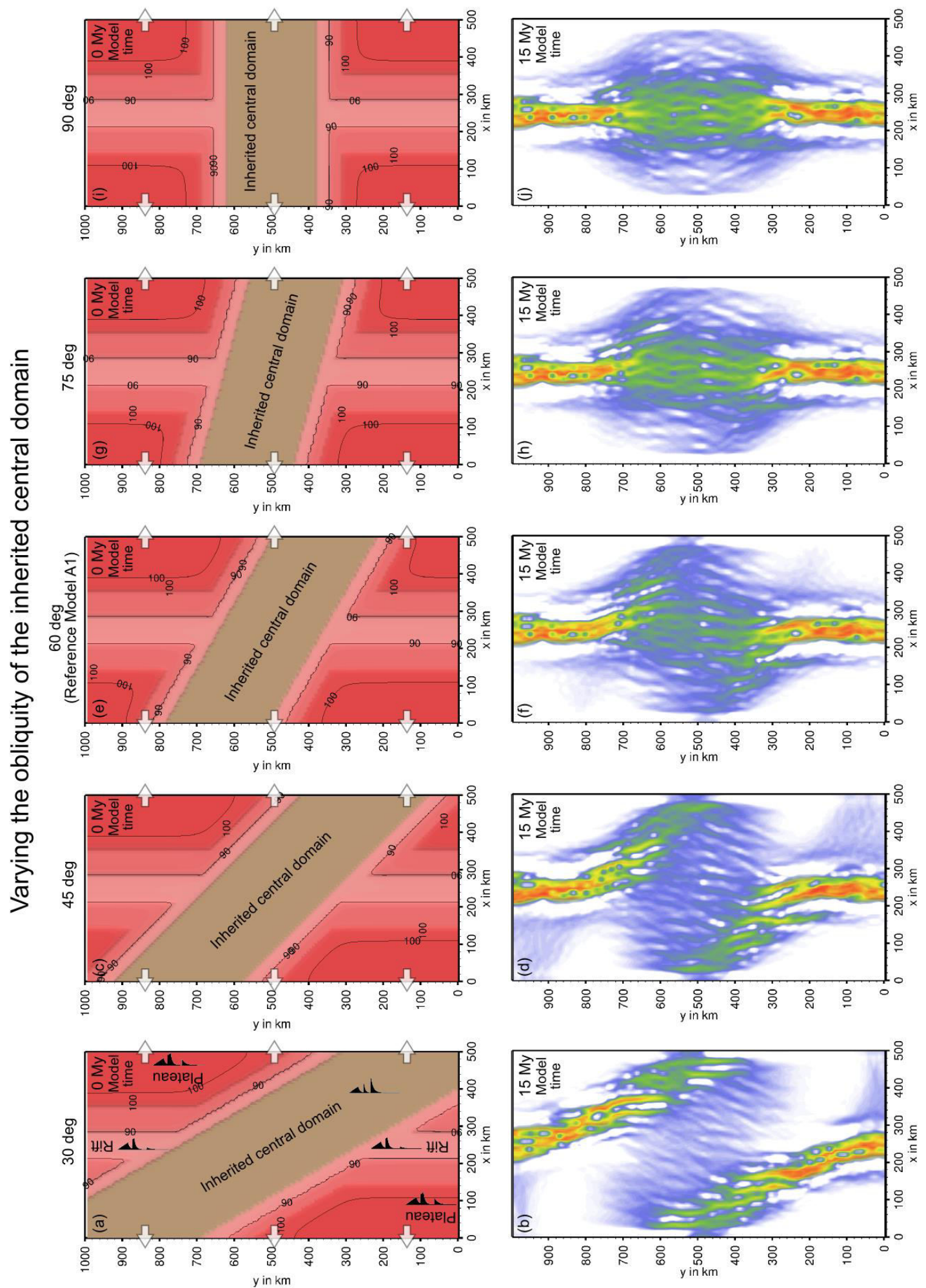

Initial depth of $1300^{\circ} \mathrm{C}$ Isotherm [km]

$\begin{array}{lllllll}0 & 20 & 40 & 60 & 80 & 100 & 120\end{array}$
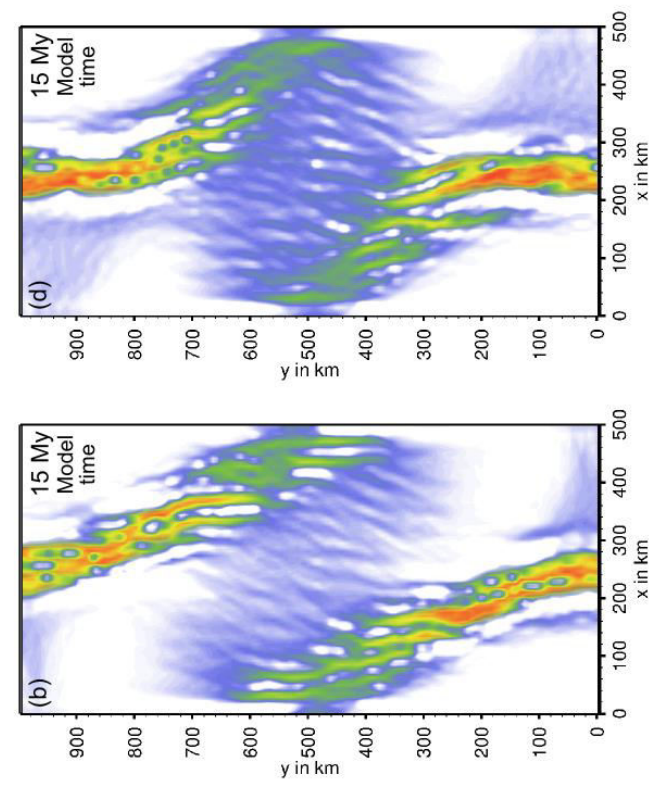

Logarithmic Strain Rate [1/s]

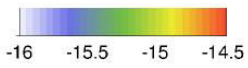

Supplementary Figure S2: Variation of the obliquity of the inherited central domain (measured between the domain trend and the extension normal). All other parameters are identical to model A1. For higher obliquities, the effect that the rifts avoid cutting into the transversal domain is enhanced. For low obliquities the effect is less pronounced and at no obliquity it disappears. 
Brune, S., Corti, G., Ranalli, G., 2017, Tectonics, 36, doi:10.1002/2017TC004739.

\begin{tabular}{|l|c|c|c|c|c|}
\hline Parameter & Units & $\begin{array}{c}\text { Upper } \\
\text { Crust }\end{array}$ & $\begin{array}{c}\text { Lower } \\
\text { Crust }\end{array}$ & $\begin{array}{c}\text { Strong } \\
\text { Mantle }\end{array}$ & $\begin{array}{c}\text { Weak } \\
\text { Mantle }\end{array}$ \\
\hline Density & $\mathrm{kg} \mathrm{m}^{-3}$ & 2700 & 2850 & 3280 & 3300 \\
\hline Thermal expansivity & $10^{-5} \mathrm{~K}^{-1}$ & 2.7 & 2.7 & 3.0 & 3.0 \\
\hline Bulk modulus & $\mathrm{GPa}$ & 55 & 63 & 122 & 122 \\
\hline Shear modulus & $\mathrm{GPa}$ & 36 & 40 & 74 & 74 \\
\hline Heat capacity & $\mathrm{J} \mathrm{kg}^{-1} \mathrm{~K}^{-1}$ & 1200 & 1200 & 1200 & 1200 \\
\hline Heat conductivity & $\mathrm{W} \mathrm{K}^{-1} \mathrm{~m}^{-1}$ & 2.5 & 2.5 & 3.3 & 3.3 \\
\hline Radiogenic heat production & $\mu \mathrm{W} \mathrm{m}^{-3}$ & 0.8 & 0.2 & 0.0 & 0.0 \\
\hline Initial friction coefficient & - & 0.5 & 0.5 & 0.5 & 0.5 \\
\hline Cohesion & $\mathrm{MPa}$ & 5.0 & 5.0 & 5.0 & 5.0 \\
\hline Rheology & & $\begin{array}{c}\text { Wet } \\
\text { Quartzite }\end{array}$ & $\begin{array}{c}\text { Wet } \\
\text { Anorthite }\end{array}$ & $\begin{array}{c}\text { Dry } \\
\text { Olivine }\end{array}$ & $\begin{array}{c}\text { Wet } \\
\text { Olivine }\end{array}$ \\
\hline Flow law reference & & $\begin{array}{c}\text { Gleason } \\
\& \text { Tullis } \\
(1995)\end{array}$ & $\begin{array}{c}\text { Rybacki } \\
\& \text { Dresen } \\
(2000)\end{array}$ & $\begin{array}{c}\text { Hirth \& } \\
\text { Kohlstedt } \\
(2003)\end{array}$ & $\begin{array}{c}\text { Hirth \& } \\
\text { Kohlstedt } \\
(2003)\end{array}$ \\
\hline Pre-exponential constant & $\mathrm{Pa}^{-\mathrm{n}} \mathrm{s}^{-1}$ & $8.57 \mathrm{e}-28$ & $1.79 \mathrm{e}-15$ & $6.51 \mathrm{e}-16$ & $2.12 \mathrm{e}-15$ \\
\hline Power law exponent & - & 4.0 & 3.0 & 3.5 & 3.5 \\
\hline Activation energy & $\mathrm{kJ}^{-3} \mathrm{~mol}^{-3}$ & 223 & 356 & 530 & 480 \\
\hline Activation volume & $\mathrm{cm}^{-1} / \mathrm{mol}^{2}$ & 0 & 0 & 13 & 10 \\
\hline
\end{tabular}

Supplementary Table 1. Thermo-mechanical modeling parameters for the numerical model. All flow laws are based on laboratory measurements for dislocation creep. 


\begin{tabular}{|c|c|c|c|c|c|c|}
\hline Name & $\begin{array}{c}\text { Full Crust } \\
\text { Thickness } \\
{[\mathrm{km}]}\end{array}$ & $\begin{array}{c}\text { Upper Crust } \\
\text { Thickness } \\
{[\mathrm{km}]}\end{array}$ & $\begin{array}{c}\text { Lithosphere } \\
\text { Thickness } \\
{[\mathrm{km}]}\end{array}$ & $\begin{array}{c}\text { Crustal } \\
\text { Strength } \\
{[\mathrm{TN} / \mathrm{m}]}\end{array}$ & $\begin{array}{c}\text { Mantle } \\
\text { Strength } \\
{[\mathrm{TN} / \mathrm{m}]}\end{array}$ & $\begin{array}{c}\text { Linkage } \\
\text { Type }\end{array}$ \\
\hline B1 & 30 & 25 & 60 & 1.03 & 0.08 & 4 \\
\hline B2 & 30 & 25 & 70 & 1.25 & 0.33 & 4 \\
\hline B3 & 30 & 25 & 80 & 1.5 & 1.23 & 1 \\
\hline B4 & 30 & 25 & 90 & 1.79 & 3.2 & 1 \\
\hline B5 =A5 & 30 & 20 & 60 & 1.11 & 0.09 & 4 \\
\hline B6 & 30 & 20 & 70 & 1.48 & 0.41 & 4 \\
\hline $\mathrm{B} 7=\mathrm{A} 1$ & 30 & 20 & 80 & 2.15 & 1.61 & 1 \\
\hline B8 & 30 & 20 & 90 & 3.02 & 3.74 & 1 \\
\hline B9 & 30 & 15 & 60 & 1.83 & 0.1 & 4 \\
\hline$B 10=A 6$ & 30 & 15 & 70 & 2.62 & 0.48 & 5 \\
\hline B11 & 30 & 15 & 80 & 3.44 & 1.93 & 2 \\
\hline B12 & 30 & 15 & 90 & 4.26 & 4.17 & 2 \\
\hline B13 & 30 & 10 & 60 & 2.42 & 0.11 & 4 \\
\hline B14 & 30 & 10 & 70 & 3.06 & 0.54 & 5 \\
\hline B15 & 30 & 10 & 80 & 3.76 & 2.16 & 2 \\
\hline B16 & 30 & 10 & 90 & 4.5 & 4.48 & 2 \\
\hline B17 & 25 & 25 & 60 & 1.00 & 0.37 & 1 \\
\hline $\mathrm{B} 18=\mathrm{A} 2$ & 25 & 25 & 70 & 1.22 & 1.63 & 1 \\
\hline B19 & 25 & 25 & 80 & 1.43 & 3.50 & 1 \\
\hline B20 & 25 & 25 & 90 & 1.66 & 5.63 & 2 \\
\hline B21 & 25 & 20 & 60 & 1.07 & 0.5 & 1 \\
\hline B22 & 25 & 20 & 70 & 1.42 & 2.04 & 1 \\
\hline$B 23=A 3$ & 25 & 20 & 80 & 2.04 & 4.03 & 2 \\
\hline B24 & 25 & 20 & 90 & 2.81 & 6.3 & 2 \\
\hline B25 & 25 & 15 & 60 & 1.74 & 0.6 & 1 \\
\hline B26 & 25 & 15 & 70 & 2.53 & 2.29 & 1 \\
\hline B27=A4 & 25 & 15 & 80 & 3.31 & 4.38 & 3 \\
\hline B28 & 25 & 15 & 90 & 3.98 & 6.77 & 3 \\
\hline B29 & 25 & 10 & 60 & 2.35 & 0.68 & 5 \\
\hline B30 & 25 & 10 & 70 & 2.98 & 2.48 & 1 \\
\hline B31 & 25 & 10 & 80 & 3.62 & 4.64 & 3 \\
\hline B32 & 25 & 10 & 90 & 4.15 & 7.11 & 3 \\
\hline $\begin{array}{l}\text { Kenya/ } \\
\text { Ethiopia } \\
\text { Rifts } \\
\end{array}$ & 40 & 20 & 90 & 3.11 & 0.31 & - \\
\hline $\begin{array}{l}\text { Plateaus } \\
\text { Outside } \\
\text { of Rifts }\end{array}$ & 40 & 20 & 100 & 4.0 & 0.85 & - \\
\hline
\end{tabular}

Supplementary Table 2. Numerical model configurations. This table lists initial layer thicknesses, crust and mantle strength along with final linkage type for all numerical models. Strain rate patterns of all models are shown in Fig. 7 of the main manuscript. 